\title{
Modelling of Damage Evolution in Braided Composites: Recent Developments
}

\author{
Chen Wang ${ }^{1,2,3}$, Anish Roy ${ }^{2}$, Vadim V. Silberschmidt ${ }^{2}$ and Zhong Chen ${ }^{1 *}$
}

\begin{abstract}
Composites reinforced with woven or braided textiles exhibit high structural stability and excellent damage tolerance thanks to yarn interlacing. With their high stiffness-to-weight and strength-to-weight ratios, braided composites are attractive for aerospace and automotive components as well as sports protective equipment. In these potential applications, components are typically subjected to multi-directional static, impact and fatigue loadings. To enhance material analysis and design for such applications, understanding mechanical behaviour of braided composites and development of predictive capabilities becomes crucial. Significant progress has been made in recent years in development of new modelling techniques allowing elucidation of static and dynamic responses of braided composites. However, because of their unique interlacing geometric structure and complicated failure modes, prediction of damage initiation and its evolution in components is still a challenge. Therefore, a comprehensive literature analysis is presented in this work focused on a review of the state-of-the-art progressive damage analysis of braided composites with finite-element simulations. Recently models employed in the studies on mechanical behaviour, impact response and fatigue analyses of braided composites are presented systematically. This review highlights the importance, advantages and limitations of as-applied failure criteria and damage evolution laws for yarns and composite unit cells. In addition, this work provides a good reference for future research on FE simulations of braided composites.
\end{abstract}

Keywords: Braided composite, Damage evolution, Finite-element model, Failure criteria, Mechanical behaviour, Impact behaviour, Fatigue

\section{Introduction}

Braiding is a method used to interweave two or more fibre yarns to produce textile composites. The angle between the longitudinal direction of a braided preform and bias yarns is generally defined as braiding angle $\theta$; it ranges typically from $15^{\circ}$ to $75^{\circ}$. Both two-dimensional (2D) and three-dimensional (3D) braided architectures can be fabricated in many ways, such as two-step or four-step method of rectangular braiding, tri-axial braiding, circular braiding, and other displacement braiding techniques (Bilisik 2012). The main feature of a braided method is its flexibility to achieve variable geometric shapes with high volumes of parts in a cost-effective way. Thanks to the unique undulations of the braided structure, macro cracks have no clear path to grow in epoxy matrix, and their propagation can be arrested at inter-sections of yarns. As a result, braided

\footnotetext{
* Correspondence: ASZChen@ntu.edu.sg

${ }^{1}$ School of Materials Science and Engineering, Nanyang Technological

University, 50 Nanyang Avenue, Singapore 639798, Singapore

Full list of author information is available at the end of the article
}

textile composites enjoy higher fracture toughness, structural stability and better damage tolerance compared to pre-preg and laminated composites (Mouritz et al. 1999). With their high stiffness-to-weight and strength-to-weight ratios, braided composites are attractive materials for aerospace and automotive components as well as sports protective equipment (Ayranci and Carey 2008).

In order to enhance understanding of braided composites, it is crucial to evaluate properties and predict their failure under static and dynamic loading. On the other hand, this topic is still quite challenging, considering complicated braided structures of such composites, rendering nonhomogeneous and anisotropic properties at the constituent level. Extensive efforts in analysis of braided textile composites have been made since 1980s, with most studies aimed at investigating their mechanical behaviour using analytical and/or experimental approaches. In analytical schemes, elastic constants of textile composites were estimated from homogenised equivalents of the representative unit cell (RUC) structure using the rule of mixtures. The 
predicted levels of strengths were generally higher than those in experimental observations; these higher values were attributed to limitations of linear elastic assumptions in the analytical expressions (Naik and Shembekar 1992; Quek et al. 2003). On the other hand, experimental studies were regarded as expensive and time-consuming. In addition, these studies did not have the capability to provide stress and strain distributions throughout braided patterns or fundamental information on damage models inside the braided composites (Miravete et al. 2006; Littell et al. 2009a, b; Xu et al. 2015a). Thus, it became necessary to seek assistance of powerful computer-aided-design (CAD) and computer-aided-engineering (CAE) tools to clarify damage mechanisms of braided structures and to predict the ultimate strength of composites with such structures.

It is not easy to develop a reliable geometrical model to simulate real braided structures due to the interlacing of yarns and complexity of the braided geometry. One of the difficulties in modelling fabric composites is an inhomogeneous distribution of fibre yarns in them. In some of the practical applications, in-plane properties of textile composites were treated as homogeneous. For instance, textile composites were represented by a composite shell (Xiao et al. 2011; Schwab et al. 2016) or layers of solid elements (Xiao et al. 2007; Yen 2002) and their stress-strain behaviours were modelled with constitutive models developed for unidirectional (UD) or woven composites; obviously, the accuracy of these models for large-tow textile composites was limited. A lack of consideration of a meso-scale structure in finite-element (FE) models was one of the reasons for such discrepancy. Therefore, a number of research teams implemented FE analysis of braided textile composites based on meso-scale geometry models. In these attempts, a RUC was used to evaluate mechanical behaviour of the whole composite structures equivalently (Pankow et al. 2012; Cousigné et al. 2013; Wan et al. 2015).

Mesoscopic structures of braided composites can be represented by various methods. A pioneering work was done by Lomov et al. (2001) who developed a software tool, WiseTex, for geometry modelling of internal structure of textile reinforcement, such as $2 \mathrm{D} / 3 \mathrm{D}$ woven, bi-axial/triaxial braided and knitted etc., transferring data into general FE codes. A similar work was carried out by a Textile Composites Research Group at the University of Nottingham in UK (Wong et al. 2006). A Python-based open-source software, TexGen, combined geometry building with volume-meshing algorithms. In addition, a well-known mosaic model and a sub-cell model (Aitharaju and Averill 1999) were developed. In the former, a composite structure was discretised into a mosaic assemblage, with each mosaic brick element having distinct material properties. Global displacement or stress could be applied to the macro level model and then transferred to mosaic blocks using iso-stress or iso-strain conditions (Bogdanovich 2009). Sub-cell FE models considered a meso-structure of textile composites in terms of simplified RUC representations. However, instead of being homogenized, the RUC was decomposed into three or four sub-cells, and their effective elastic constants were obtained by micromechanical analysis (Aitharaju and Averill 1999) employing equivalent (Zhou et al. 2013; Zhang et al. 2014a) or idealized laminate (Xiao et al. 2007). FE models for the RUCs were subsequently constructed using solid elements of each set of property according to their locations in the RUC. Based on this approach, a generalized method of cells (GMC) was developed (Qi et al. 2014; Bednarcyk et al. 2015). GMC considers a periodic repeating unit cell and is limited to four sub-cells (one for fibre and three for matrix). This theory was firstly generalised by Paley and Aboudi (1992) to consider an arbitrary number of sub-cells and constituent phases. The resulting GMC enables analysis of repeating unit cells containing more than two constituent materials, a more refined fibre shape, and various fibre architectures. Using GMC, Liu et al. (2011) built a framework for a three-scale analysis of tri-axially braided composites, and effective properties of the RUC at each scale were determined. The advantages and shortcomings of these topological meso-geometry models were pointed out by Fang and Liang (2011). The main advantage was that the mesoscale models obtained with these methods could be meshed easily. However, this scheme faced the challenges of internal continuity and stress-singularity problems, which were caused by distinctive elastic properties of two adjacent mosaic blocks (Dai and Cunningham, 2016). Also, realistic meso-geometrical configurations were ignored in the topological methods. Recently, virtual descriptions of the geometries of braided textiles were developed using 3D SolidWorks and CATIA (Ji et al. 2014; Wang et al. 2016b). These versatile geometric unit cells were highly flexible and dynamic in nature, capable of simulating textile tightening, accommodated by yarn deformation and spatial constraint. The unit-cell geometries were then fed into $\mathrm{FE}$ analysis packages to determine their individual and continuum-mechanical characteristics (Ji et al. 2014).

To date, many authors in failure prediction in braided composites are adopting these geometrical models as shown in Fig. 1. In contrast, damage models suitable for braided composites are still under investigation since their failure behaviours are complicated and failure modes can vary under different loading conditions. For decades, the progressive-failure analysis (PFA) of UD laminated composites was applied to both braided and woven composite structures. When the PFA of composites is conducted, failure criteria and degradation models of constitutive material properties are the two most important aspects for consideration. The failure criteria are the conditions 


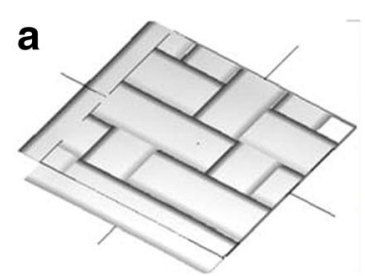

d

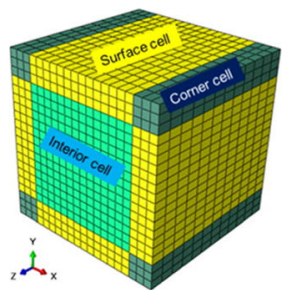

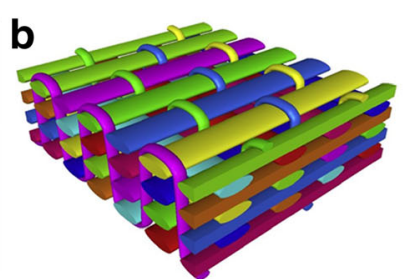

e

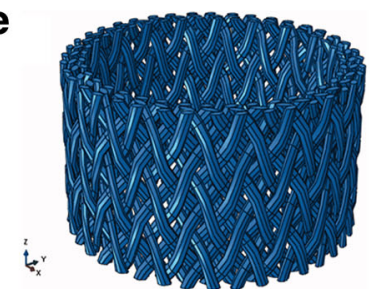

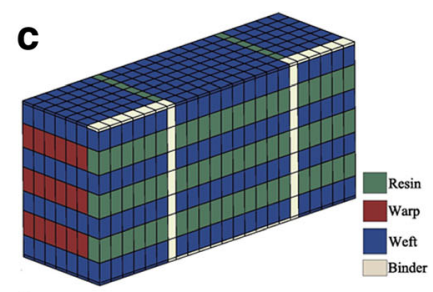

$\mathbf{f}$

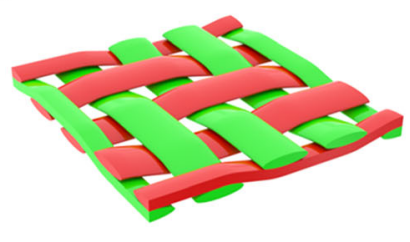

Fig. 1 Geometrical models of braided composites by means: a WiseTex (Xu et al. 2016); b TexGen (Dai and Cunningham 2016); c the mosaic model (Dai and Cunningham 2016); d the sub-cell model (Wan et al. 2015); e CATIA (Gideon et al. 2015); f SolidWorks (Ji et al. 2014)

for evaluation of the occurrence of material damage. With development of studies on damage mechanisms of composites, although multiple failure criteria for composites were suggested, even a most accepted failure criterion might not be suitable for all the conditions.

The degradation models are mathematical representations of residual properties for each material damage state predicted with the failure criteria (Garnich and Akula, 2009). The most direct way for damage modelling is a fracture-mechanics-based approach, in which cracks are directly introduced into the model. Still, introducing cracks inside complex yarns-matrix architecture and remeshing are computationally intensive. Continuum damage mechanics (CDM), which can provide a tractable framework for modelling damage initiation and development with a strategy of stiffness degradation, is one of the important and effective methods to model progressive damage behaviour of fibre-reinforced composites supported by FE procedures. The main advantage of CDM is the straightforwardness with implementation into FE analysis; since the material is continuous throughout the damage process, it does not require re-meshing (Murakami 2012). CDM provides not only the final failure load, but also information concerning the extent of integrity of the material during the load history.

Ansar et al. (2011) systematically reviewed the modelling techniques along with their capabilities and limitations for characterization of the micro-geometry, mechanical behaviour and impact behaviour of 3D woven composites. A comprehensive literature survey was also conducted by Fang and Liang (2011) to review the methods of numerical analysis for 3D braided composites, including meso-scale modelling, mesh-generation techniques and progressivedamage models. These review papers indicated that although various damage degradation schemes based on
CDM were suggested, a universal model of damage mechanics, accounting for different loading conditions, failure modes, damage initiation and evolution, is still lacking.

In order to improve efficiency and accuracy of simulation work, scientists continued to develop various state-ofthe-art damage-evolution methods for braided composites in past few years. Based on the review works by Ansar et al. (2011) and Fang and Liang (2011), the objective of this paper is to review recent developments made in failure analysis of braided composites. Most of the studies discussed herein were published after 2011. The contents are organised as follows: First, acceptable failure criteria and advanced damage-evolution models for predicting mechanical response of braided composites are discussed. Then, recent numerical studies on impact behaviour are introduced. Last but not least, modelling strategies of fatigue damage are provided.

\section{Review \\ Modelling mechanical behaviour of braided composites}

Most numerical attempts considering mechanical behaviour of braided composites are developed from previous FE schemes for laminates and, in some cases, woven textile composites. Such studies mainly focus on predicting effective elastic moduli and tensile strength of braided composites (Rawal et al. 2015). In order to study their mechanical response including final failure, an accurate model should account for the dominant damage mechanisms (e.g., fibre fracture, fibre kinking, matrix cracking and delamination) and complex interactions among them. Furthermore, it is preferred for damage models to capture the effects of interlacing and undulation of fibre yarns in meso-scale unit cells. This section introduces some recent predictive models developed by various authors to evaluate damage of braided composites under static loading. 


\section{Criteria for failure initiation}

A typical progressive-damage model (PDM) comprises three parts: stress analysis, failure analysis and materialproperty degradation (Zhou et al. 2013). These parts are implemented in an iterative procedure performed until the final failure occurs. The stress analysis is linked to appropriate constitutive relationships for both undamaged and damaged materials, which requires adequate damage-initiation criteria revealing main failure mechanisms and compatible with FE models. A specific damage-evolution model is needed to describe materialproperty degradation after damage initiation. To date, the failure criteria, applied predominantly to braided composites, are still developed from classical damage theories of laminated composites. Garnich and Akula (2009) reviewed some of the most commonly applied criteria for UD fibre-reinforced polymers and classified them into either mode-dependent or mode-independent criteria.

Nowadays, two categories of failure criteria are actively pursued. Mode-independent failure criteria use mathematical expressions to depict a damage surface as a function of strength of materials. All the polynomial and tensorial criteria belong to such a category. Tsai- $\mathrm{Wu}$ criteria are the most well-known and general one for composites, belonging to a type of Tensor Polynomial Criterion (Tsai and Wu 1971). For practical proposes, the polynomial criterion is expressed in tensor notation as (Hart-Smith, 1998)

$$
F_{i} \sigma_{i}+F_{i j} \sigma_{i} \sigma_{j} \geq 1
$$

where $i, j=1 \ldots 6$. The parameters $F_{i}$ and $F_{i j}$ are related to the composite strength in the principal directions. Considering that failure of the material is insensitive to a change of sign in shear stresses, all terms containing a shear stress to first power must vanish: $F_{4}=F_{5}=F_{6}=0$. Then, the explicit form of the general expression is:

$$
\begin{aligned}
F_{1} \sigma_{1} & +F_{2} \sigma_{2}+F_{3} \sigma_{3}+2 F_{12} \sigma_{1} \sigma_{2}+2 F_{23} \sigma_{2} \sigma_{3} \\
& +2 F_{13} \sigma_{1} \sigma_{3}+F_{11} \sigma_{1}^{2}+F_{22} \sigma_{2}^{2}+F_{33} \sigma_{3}^{2} \geq 1 .
\end{aligned}
$$

In recent studies, the Tsai-Wu tensor polynomial failure criterion was used by McLendon and Whitcomb
(2012) and Wang et al. (2017b) to identify, which location (s) in the tows are the first to fail under a given loading. Jiang et al. (2013) modified this criterion considering an additional bending stress and the interaction force between curved yarns to determine longitudinal strength of 3D braided composites under a uniaxial load. Cousigné et al. (2013) applied the Tsai-Wu criterion to predict mechanical failure of woven composites and mentioned that the criterion offered a smooth continuous ellipsoidal failure surface efficiently without involving specific and complex failure modes, as shown in Fig. 2. Wan et al. (2015) used Hill's anisotropic plasticity model to predict failure of fibre tows. Hill's potential function is a simple extension of the Mises function, which can be expressed in terms of rectangular Cartesian stress components. Besides the Tsai-Hill criterion (1968), several other similar quadratic criteria have been proposed by Hoffman (1967) and Chamis (1969). These criteria can be considered as generalized Tsai-Wu type criteria.

Traditional ply-based failure criteria, such as Tsai-Wu and Tsai-Hill, consider a yarn-matrix system as a whole and, therefore, they are not suitable to predict whether the failure occurs inside a yarn, a matrix, or at their interfaces (Tolosana et al. 2012). When characterising failure of composites, researches focus on their homogeneity rather than anisotropic nature. This is inappropriate since internal unique structures of composites influence their properties and failure character (Paris and Jackson 2001). Moreover, the polynomial criteria may be not suitable in design, particularly for bi-axial tensile loading (Edge 2002). Considering a non-homogeneous character of braided composites, mode-dependent criteria were proposed.

Mode-dependent criteria are generally established in terms of mathematical expressions based on material strengths. They consider different failure modes of the constituents. Because of this advantage, these criteria are adequate for PFA. Two of the simplest examples are the maximum-stress and maximum-strain criteria. The former criterion predicts that composites fail when the stress exceeds the maximum tolerance value. Three different conditions of failure are considered for a maximum stress in a longitudinal direction, a transversal direction and for shear stresses:
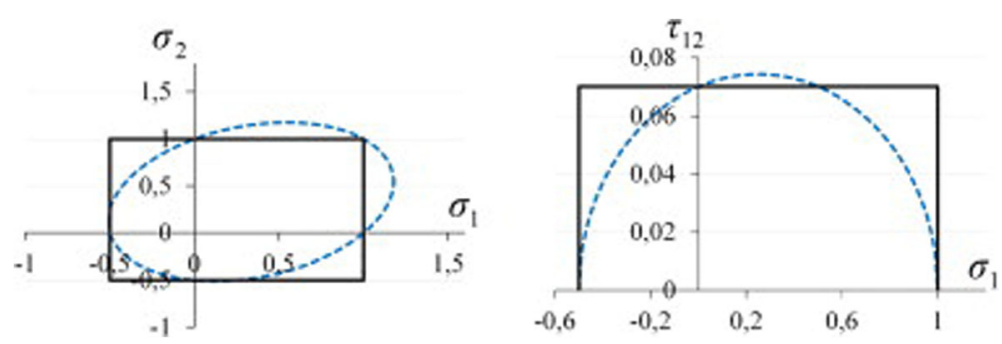

Fig. 2 Failure surfaces of maximum-stress (solid line) and Tsai-Wu (dashed blue line) failure criteria (Cousigné et al. 2013) 
Longitudinal:

$$
\sigma_{1} \geq X_{T} \text { or }\left|\sigma_{1}\right| \geq X_{C} ;
$$

Transverse:

$$
\sigma_{2} \geq Y_{T} \text { or }\left|\sigma_{2}\right| \geq Y_{C} ;
$$

Shear:

$$
\tau_{12} \geq S_{12} \text { or }\left|\tau_{23}\right| \geq S_{23}
$$

In Eqs. (3)-(5), $X_{T}$ and $Y_{T}$ denote tensile strengths in the longitudinal $(X)$ and transverse $(Y)$ directions of a braided composite, respectively. $X_{C}$ and $Y_{C}$ are compressive strengths in the $X$ and $Y$ direction of the composite, respectively. Indices 1,2 and 3 are used to describe $X, Y$ and $\mathrm{Z}$ directions, respectively. Hence, $S_{12}, S_{13}$ and $S_{23}$ signify in-plane and two out-of-plane shear strengths, respectively. The effective normal and shear stress component are denoted by $\sigma_{i}$ and $\tau_{i j}(i, j=1,2,3 ; i \neq j)$, respectively.

Similarly, the maximum-strain criterion means that when the strain exceeds the given allowable value, the constitutive materials fail. These maximum criteria can be used for homogeneous textile composite models (Sevkat et al. 2009a, b). As simple methods to analyses composites failure, the major limitation of the maximum-stress and maximum-strain criteria is that they ignore the interaction between stresses and strains in the composites. Therefore, they were mostly applied to specific constitutive material elements, such as failure of fibre (Mao et al. 2013), yarns (Dai and Cunningham, 2016) or pure matrix resin (Sun et al. 2013; Qi et al. 2014).

In contrast, some mode-dependent failure criteria take into account interactions between stresses and strains (they are called interactive failure criteria), including Hashin (1980), Puck and Schürmann (1998) and micro mechanics-based failure (MMF) criteria (Ha et al. 2010). Hashin proposed different failure modes associated with the fibre tow and the matrix, considering, in both modes, differences in tension and compression (Hashin 1980), as shown in Fig. 3. The values of initiation damage criteria $\varnothing_{I}$ for each type of failure mode $I$ are as follows:

Fibre tensile failure in longitudinal direction $\varnothing_{L}^{t}:\left(\sigma_{1} \geq 0\right)$

$$
\varnothing_{L}^{t}=\left(\frac{\sigma_{1}}{X_{T}}\right)^{2}+\phi\left[\alpha \frac{\tau_{12}^{2}}{\left(S_{12}\right)^{2}}+\alpha \frac{\tau_{13}^{2}}{\left(S_{13}\right)^{2}}\right]=1
$$

Fibre compressive failure in longitudinal direction $\varnothing_{L}^{c}:\left(\sigma_{1}<0\right)$

$$
\varnothing_{L}^{c}=\left(\frac{\sigma_{1}}{X_{C}}\right)^{2}=1
$$

Matrix tensile failure in transverse direction $\varnothing_{Y}^{t}$ : $\left(\sigma_{2}+\sigma_{3} \geq 0\right)$

$$
\varnothing_{Y}^{t}=\left(\frac{\sigma_{2}+\alpha \sigma_{3}}{Y_{T}}\right)^{2}+\alpha \frac{\tau_{23}^{2}-\sigma_{2} \sigma_{3}}{\left(S_{23}\right)^{2}}+\frac{\tau_{12}^{2}}{\left(S_{12}\right)^{2}}+\alpha \frac{\tau_{13}^{2}}{\left(S_{13}\right)^{2}}=1
$$

Matrix compressive failure in transverse direction $\varnothing_{Y}^{c}$ : $\left(\sigma_{2}+\sigma_{3}<0\right)$

$$
\begin{aligned}
\varnothing_{Y}^{c}= & {\left[\left(\frac{Y_{C}}{2 S_{23}}\right)^{2}-1\right] \frac{\sigma_{2}+\alpha \sigma_{3}}{Y_{C}}+\left(\frac{\sigma_{2}+\alpha \sigma_{3}}{2 S_{23}}\right)^{2}+\alpha \frac{\tau_{23}^{2}-\sigma_{2} \sigma_{3}}{\left(S_{23}\right)^{2}} } \\
& +\frac{\tau_{12}^{2}}{\left(S_{12}\right)^{2}}+\alpha \frac{\tau_{13}^{2}}{\left(S_{13}\right)^{2}}=1 .
\end{aligned}
$$

In Eqs. (6)-(9), a plane-stress factor in each mode is represented with $\alpha$. When the through-thickness stress component is ignored, $\alpha=0$. Otherwise, in a 3D case, $\alpha=1$. In the tensile fibre failure criteria, the coefficient $\phi$ is employed to determine the contribution of shear stress to the initiation of fibre tensile failure. The planar Hashin's failure criteria with CDM degradation models controlled by energy-dissipation constants are implemented in ABAQUS, but only available for shell elements. Li et al. (2011) and Zhang et al. 2014, 2015a, b) applied the planar Hashin's method to predict mechanical behaviour of braiding structures. In order to use 3D elements in ABAQUS, the Hashin's 3D failure criteria were usually implemented in a user-defined subroutine (Warren et al. 2016; Zhang et al. 2017a). When the braided composites were regarded as orthotropic materials, failure modes in the thickness direction, as shown below, should be considered (Kang et al. 2016):

Matrix tensile failure in thickness direction $\varnothing_{Z}^{t}\left(\sigma_{3} \geq 0\right)$ :

$$
\varnothing_{Z}^{t}=\left(\frac{\sigma_{3}}{Z_{T}}\right)^{2}+\frac{\sigma_{23}}{S_{23}}+\frac{\tau_{13}^{2}}{\left(S_{13}\right)^{2}}=1 ;
$$

Matrix compressive failure in thickness direction $\varnothing_{Z}^{c}$ $\left(\sigma_{3}<0\right)$ :

$$
\varnothing_{Z}^{c}=\left(\frac{\sigma_{3}}{Z_{C}}\right)^{2}+\frac{\sigma_{23}}{S_{23}}+\frac{\tau_{13}^{2}}{\left(S_{13}\right)^{2}}=1 .
$$

In Eqs. (10) and (11), $Z_{T}$ and $Z_{C}$ denote tensile and compressive strengths in the through-thickness $(Z)$ direction of a braided composite, respectively. In some studies, criteria for thickness-direction failure modes were presented in other forms (Fang et al. 2009; Zhou et al. 2013).

It has to be mentioned that once this distinction, based on the failure mechanism, is made, the author's strategy is to apply logical reasoning to derive an applicable criterion, rather than to continue with the mechanism of failure to establish the associated macro-variables. Thus, for the matrix mode, Hashin proposed a quadratic criterion 


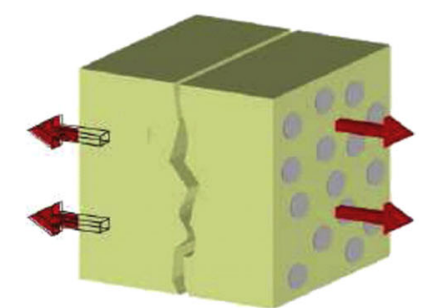

Fibre Tensile Failure

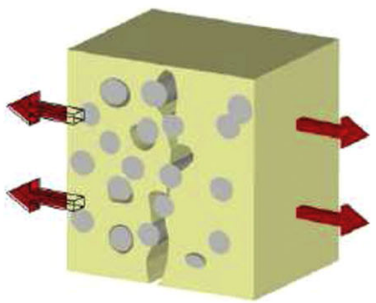

Matrix Tensile Failure

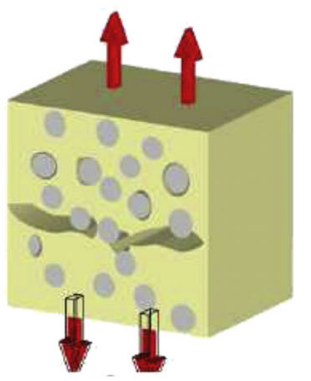

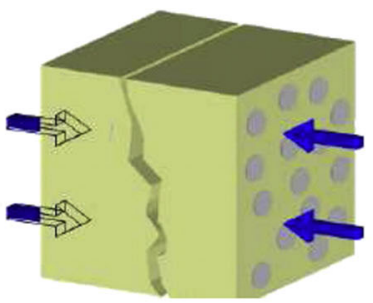

Fibre Compressive Failure

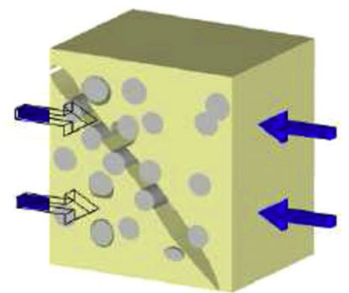

Matrix Compressive Failure

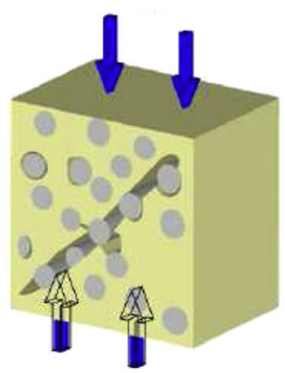

\section{Matrix Failure in Thickness Direction}

Fig. 3 Illustration of failure modes described in Hashin-type failure criteria (Doitrand and Fagiano 2015)

because, on the one hand, a linear criterion underestimated strength of the material and, on the other hand, a polynomial of higher degree would be too complicated to manage (Hashin 1980; Paris and Jackson 2001). Although Hashin himself limited the scope of his proposal to UD composites, the criteria were widely applied to braided composites in recent years (Binienda 2012; Zhang et al. 2014a; 2014b; Zhou et al. 2013).

So far, the mode-dependent failure criteria were proved to be more suitable for analysis of failure initiation in braided composites. Comparing to the Hashin's failure criteria, even more failure modes were considered in some studies. Doitrand and Fagiano (2015) applied an advanced failure criterion including different damage mechanisms such as fibre failure, transverse and out-of-plane cracking for the yarns, and inter-yarnmatrix cracking to study mechanical behaviour of a four-layer plain-weave glass fibre/epoxy matrix composite at the mesoscopic scale. It should be noted that the mode-dependent failure criteria can be also presented in a strain-based form, e.g. the Hashin straintype criteria and a Linde criterion ( $\mathrm{Lu}$ et al. 2013; Zhang et al. 2016a).

Micro-mechanics of failure is a theory that links constitutive materials (individual fibre, matrix and their interface) and a macroscopic stress response of composites (Ha et al. 2008). It is believed that failure of fibrous composites can be assessed with micro-scale analysis. No difference between tension and compression failure modes at constituent levels is considered, and failure of fibre-matrix interface is incorporated:

fibre failure:

$$
\begin{aligned}
& X_{C}<\sigma_{1}<X_{T}, \\
& \sum_{i=1}^{6} \sum_{j=1}^{6} F_{i j} \sigma_{i} \sigma_{j}+\sum_{i=1}^{6} F_{i} \sigma_{i}=1,
\end{aligned}
$$

matrix failure: 


$$
\frac{\sigma_{V \text { Mises }}^{2}}{C_{m} T_{m}}+\left(\frac{1}{T_{m}}-\frac{1}{C_{m}}\right) I_{1}=1
$$

interface failure:

$$
\left(\frac{\left\langle t_{n}\right\rangle}{Y_{n}}\right)^{2}+\left(\frac{t_{s}}{Y_{s}}\right)^{2}=1
$$

A fibre is a transversely isotropic material, and two possible failure criteria are needed for its failure. The first is a simple maximum-stress criterion; the other is the Tsai-Wu criterion. It was argued that the adoption of quadratic failure criteria, such as the Tsai- $\mathrm{Wu}$, required the values of transverse tensile and compressive as well as shear strengths, which were difficult to obtain in experiments. So, a simplification of the quadratic criteria to the maximum-stress criteria was preferred (Ha et al. 2010). The epoxy matrix is regarded as isotropic, and has a higher strength value under uniaxial compression than under tension. For the matrix, a Christensen Criterion was applied, which is a modified version of the von Mises failure criterion (Christensen 2007). Finally, the fibre-matrix interface can be considered to follow a traction-separation failure criterion (Ha et al. 2008, 2010).

MMF has gradually gained credibility as evident in the recent Second World-Wide Failure Exercise (WWFE II). MMF was reported to be able to predict successfully both the initial and final failures for all the 12 specified test cases (Kaddour and Hinton 2012). MMF is different from conventional methods primarily in two ways. On the one hand, the conventional methods are the ply-level failure methods while MMF is based on the constituent's failure. On the other hand, the conventional macro-level methods generally require one or more interaction parameters in order to capture the interaction of stress components in the matrix and fibres, while MMF uses a micromechanical model to account for the stress interaction, so that the interaction parameter is not needed (Xu et al. 2015a, b). A modified MMF scheme was proposed to improve predictions of shear strength by adding shear component in the criteria (Ha et al. 2010). In addition, since $\sigma_{11}$ component was closely related with fibre failure, it was assumed that $\sigma_{11}$ did not contribute to matrix failure. Thus, the MMF scheme was simplified to three-parameter MMF (MMF3):

$$
\begin{gathered}
\left(\frac{1}{T_{m}}-\frac{1}{C_{m}}\right)\left(\sigma_{22}+\sigma_{33}\right)+\frac{1}{T_{m} C_{m}}\left(\sigma_{22}+\sigma_{33}\right)^{2} \\
-\frac{1}{S_{m}^{2}}\left[\sigma_{22} \sigma_{33}-\left(\tau_{12}^{2}+\tau_{23}^{2}+\tau_{31}^{2}\right)\right]=1
\end{gathered}
$$

\section{Damage mechanics}

To model progressive failure of braided textile composites, numerous studies combined two damage- evolution theories for inter- and intra-laminar damages, respectively. The first theory was a cohesive zone model (CZM), widely used to capture interlaminar delamination (Xie et al. 2006). Application of CZM requires a-priori knowledge of an intended crack path and a use of cohesive elements. Another theory to evaluate intra-laminar failure was continuum damage mechanics (CDM) (Camanho et al. 2003; Heinrich et al. 2013). In CDM, damage is described by introducing internal state variables $\left(D_{i j}\right)$ into an algorithm of continuum mechanics to represent micro defects in a damage process in the material. Stiffness values of composites degraded with the growing damage variables (DVs) $D_{i j}$ homogeneously when a material met its failure criteria. Therefore, post-peak behaviour of materials can be described by a degraded stiffness matrix $\boldsymbol{C}\left(\boldsymbol{D}_{i j}\right)$ or compliance matrix $S\left(D_{i j}\right)$ as

$$
\begin{aligned}
\sigma_{i j}^{*} & =\boldsymbol{C}\left(\boldsymbol{D}_{i j}\right) \varepsilon_{i j} \text { or } \varepsilon_{i j}=\boldsymbol{S}\left(\boldsymbol{D}_{i j}\right) \sigma_{i j}^{*}, i, j \\
& =1,2 \text { and 3, respectively. }
\end{aligned}
$$

Although many methods were developed, it is still an open question how to define DVs considering complicated failure modes of braided composites. In this section, some stiffness-degradation approaches most broadly used in recent investigations are discussed.

\section{Instantaneous stiffness degradation}

An instantaneous stiffness-degradation method was initially developed by Blackketter et al. (1993) and Matzenmiller et al. (1995). In this empirical stiffnessreduction scheme, DVs are usually constants. When stresses at an integration point of a finite element satisfy the damage-initiation criterion, damage at this integration point happens and stiffness is reduced to a specific value according to the relevant failure mode. The scheme was widely used for damage prediction in composites without any convergence difficulties. It also showed good capability to simulate the mechanical performance of noncrimp fabric (NCF) composite structural parts associated with different failure modes of yarns subjected to tension loading (Tserpes and Labeas, 2009). A degradation factor associated with particular failure mode was used to multiply the corresponding modulus as soon as that particular mode of failure was detected. The computed damage initiation and accumulation had consistent results with experiments. However, the results indicated that the final failure load depended on the mesh size and time increment.

Recently, this degradation scheme was further developed for textile composites. Mao et al. (2013) presented a multiscale modelling approach for progressive-failure 
analysis of carbon-fibre-reinforced woven composites. Microscale damage modes of the composite material were determined by using the maximum-stress criterion for fibres and the MMF for a matrix. The mechanical response was assumed to be linear elastic until initiation of failure. The instantaneous stiffnessdegradation method was applied, as shown in Fig. 4. For an element that reached the failure criterion, the elastic constants were reduced as follows:

$$
\begin{aligned}
E_{i j}^{d} & =\left[1-(1-n)\left(1-d_{i j}\right)\right] E_{i j}^{0}, i, j \\
& =1,2 \text { and 3, respectively, }
\end{aligned}
$$

where $E_{i j}^{d}$ are the effective residual material properties of the failed element, $E_{i j}^{0}$ are the values of initial stiffness. The softening factor $n$ is computed to control the softening process. In addition, $d_{i j}$ are the degradation factors, prescribed in terms of reduction of effective stiffness along different directions. Failure analysis was carried out to provide the influence of each damage mechanism on overall laminates stiffness, and, thus, the values of $d_{i j}$ were determined by means of mesomechanical failure analysis with six cases of boundary conditions. Additionally, quantitative analysis based on virtual tests was conducted to determine the degradation factors for every damage mechanism to control the stress reduction in the damage-evolution law. The reported degradation factors are listed in Table 1 .

Warren et al. (2016) developed a 3D progressivedamage model to capture the onset and initial propagation of damage in a 3D woven composite in a single-bolt, double-shear joint. The model combined the well-established Hashin failure criteria and the Matzenmillere-Lublinere-Taylor damage model to capture bearing damage; failure indicators were used to calculate DVs. In this model, DVs affected directly elastic properties of the material by means of modification of diagonal components of a compliance matrix at each material point. For brittle materials, four DVs and all functions of the specific failure indicators, as seen in Table 2, were used to modify this material compliance matrix:
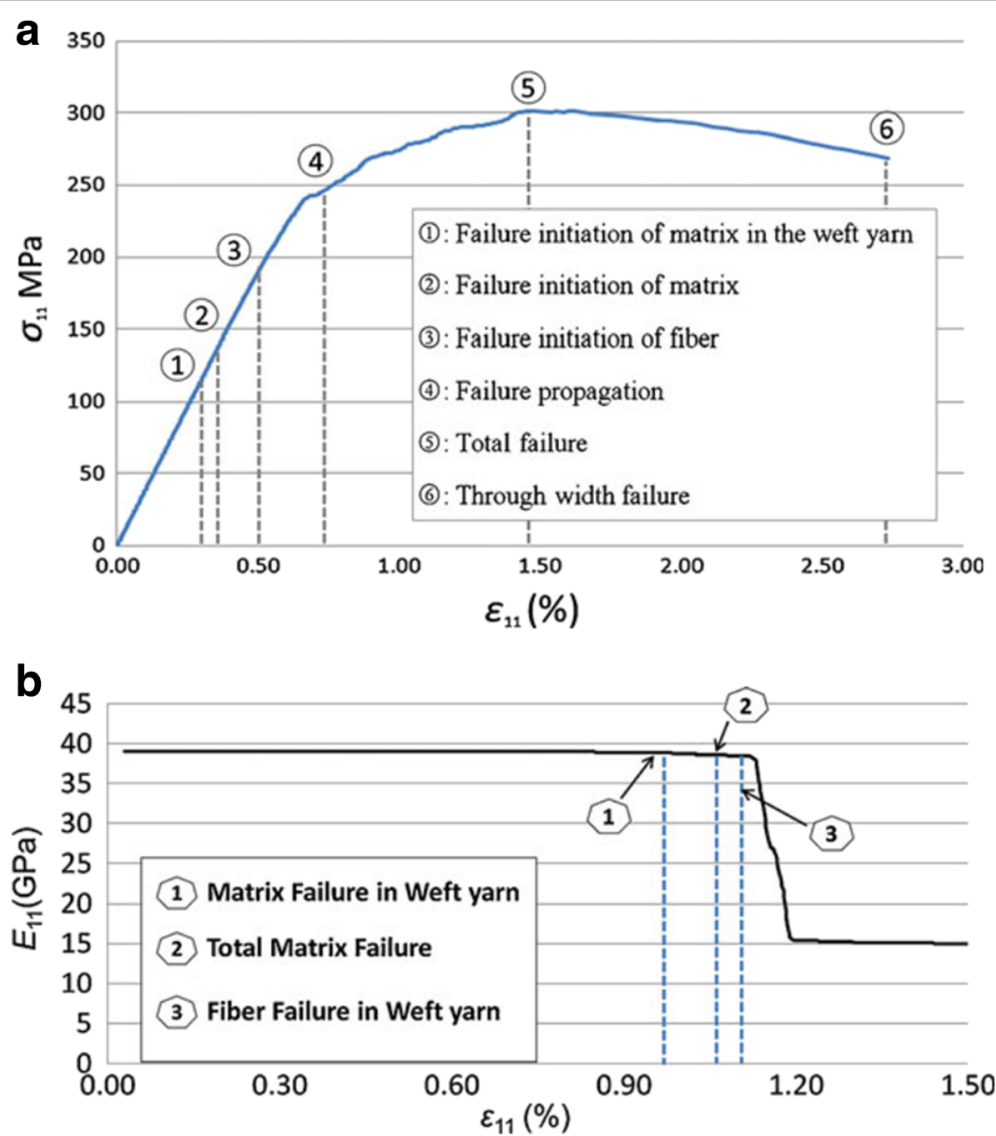

Fig. 4 Longitudinal stress-strain curve (a) and stiffness-reduction of woven-composite unit cell (b) in instantaneous stiffness-degradation method (Mao et al. 2013) 
Table 1 Degradation model for all damage mechanisms (Mao et al. 2013)

\begin{tabular}{llllll}
\hline $\begin{array}{l}\text { Degradation } \\
\text { factor }\end{array}$ & $\begin{array}{l}\text { Matrix } \\
\text { failure }\end{array}$ & $\begin{array}{l}\text { Matrix } \\
\text { failure in } \\
\text { weft yarn }\end{array}$ & $\begin{array}{l}\text { Matrix } \\
\text { failure in } \\
\text { warp yarn }\end{array}$ & $\begin{array}{l}\text { Fibre } \\
\text { failure in } \\
\text { weft yarn }\end{array}$ & $\begin{array}{l}\text { Fibre } \\
\text { failure in } \\
\text { weft yarn }\end{array}$ \\
\hline$d_{11}$ & 0.75 & 1 & 0.85 & 0.001 & 1 \\
$d_{22}$ & 0.75 & 0.85 & 1 & 1 & 0.001 \\
$d_{33}$ & 0.001 & 0.25 & 0.25 & 0.85 & 0.85 \\
$d_{12}$ & 0.01 & 0.25 & 0.25 & 0.001 & 0.001 \\
$d_{23}$ & 0.01 & 0.75 & 0.25 & 0.25 & 0.001 \\
$d_{13}$ & 0.01 & 0.25 & 0.75 & 0.001 & 0.25 \\
\hline
\end{tabular}

$$
S(d)=\left[\begin{array}{cccccc}
\frac{1}{1-d_{1}} S_{11} & S_{12} & S_{13} & 0 & 0 & 0 \\
S_{12} & \frac{1}{1-d_{2}} S_{22} & S_{23} & 0 & 0 & 0 \\
S_{13} & S_{23} & \frac{1}{1-d_{2}} S_{33} & 0 & 0 & 0 \\
& & & \frac{1}{1-d_{3}} S_{44} & 0 & 0 \\
& & & & \frac{1}{1-d_{3}} S_{55} & 0 \\
& & & & & \frac{1}{1-d_{4}} S_{66}
\end{array}\right]
$$

Its off-diagonal terms remained unaffected by DVs in order to satisfy physical and thermodynamic conditions. A similar method was applied by Wang et al. (2016a) to predict tensile strength of bi-axial braided composites with various braiding angles (Fig. 5), while studies by Ahn and Yu (2016) and Zhong et al. (2017) focused on a bending response of braided composites. Nobeen et al. (2016) stated that the appropriate reduction factors should be selected for the pure matrix and yarn damage of braided composites based on results of experiments and micro-mechanical numerical simulations. And such DVs (Eqs. (18) and (19)) were implemented in ABAQUS using the UMAT and USDFLD subroutines, respectively. They were stored as Solution

Table 2 Definition of damage variables in Warren et al. (2016)

\begin{tabular}{ll}
\hline Damage mode & Damage variable value \\
\hline Pure matrix phase & $d_{m}=0.9$ \\
Longitudinal damage (fibre) & $d_{1}=\left\{\begin{array}{cc}0.93 & \text { tesnion } \\
0.8 & \text { compression }\end{array}\right.$ \\
Transverse damage (matrix) & $d_{1}=\left\{\begin{array}{cc}0.86 & \text { tesnion } \\
0.6 & \text { compression }\end{array}\right.$ \\
Longitudinal shear (combined) & $d_{3}=1-\left(1-d_{1}\right)\left(1-d_{2}\right)$ \\
Transverse shear (combined) & $d_{4}=d_{3}$ \\
\hline
\end{tabular}

Dependent Variables and can be monitored throughout the progression of the analysis.

Although reasonable numerical results were obtained using the instantaneous stiffness-degradation method in many works, magnitudes of the stiffness-reduction factors were somewhat arbitrarily chosen by researchers based on the types of failure criteria and different failure modes. Therefore, the advanced failure criteria and damage factors for braided composites need to be investigated further, and more efforts are unquestionably needed in the future.

\section{Continuous stiffness degradation}

Evolution of DVs in the continuum stiffness-degradation method is based on a thermodynamic framework or an energy-dissipation theory. In the early stage, CDM was built to study damage development for single-ply or laminate composites because the damage mechanisms of UD composites were relatively easy to quantify. Nowadays, various evolution laws based on the continuum stiffness-degradation method are also suitable for braided composites. In these studies, the evolution of DVs could be presented in a linear or an exponential form.

When constituents of a material fail in an element, it dissipates energy equal to its elastic energy. According to an approach by Lapczyk and Maimí (Lapczyk and Hurtado, 2007; Maimí et al. 2007), a characteristic element length was introduced into an expression to solve a mesh-dependence problem. The equivalent displacement at failure point $X_{e q}^{f}$ is defined as follows:

$$
X_{e q}^{f}=\varepsilon_{I f} l
$$

where $l$ is the characteristic length of the element and $\varepsilon_{\text {If }}$ is the equivalent strain at failure of failure mode $I$. Thus, degradation of the stiffness tensor is characterized by a damage matrix, $\boldsymbol{C}(\boldsymbol{D})$, defined by internal DVs $d_{I}$ associated to different failure modes $I$ (Fang et al. 2009). When the Hashin failure criteria are applied, the DV of each failure mode is expressed by the following equivalent displacement:

$$
d_{I}=\frac{X_{e q}^{I f}\left(X_{e q}^{I}-X_{e q}^{I i}\right)}{X_{e q}^{I}\left(X_{e q}^{I f}-X_{e q}^{I i}\right)}(I=L t, L c, Y t, Y c, Z t, Z c)
$$

Figure 6 shows the linear evolution of DVs. Accordingly, $X_{e q}^{I i}$ and $X_{e q}^{I f}$ in Eq. (21) are the initiation and full damage equivalent displacements of failure mode $I$, respectively.

$X_{e q}^{I i}$ and $X_{e q}^{I f}$ could be calculated with the following equations (Kang et al. 2016): 


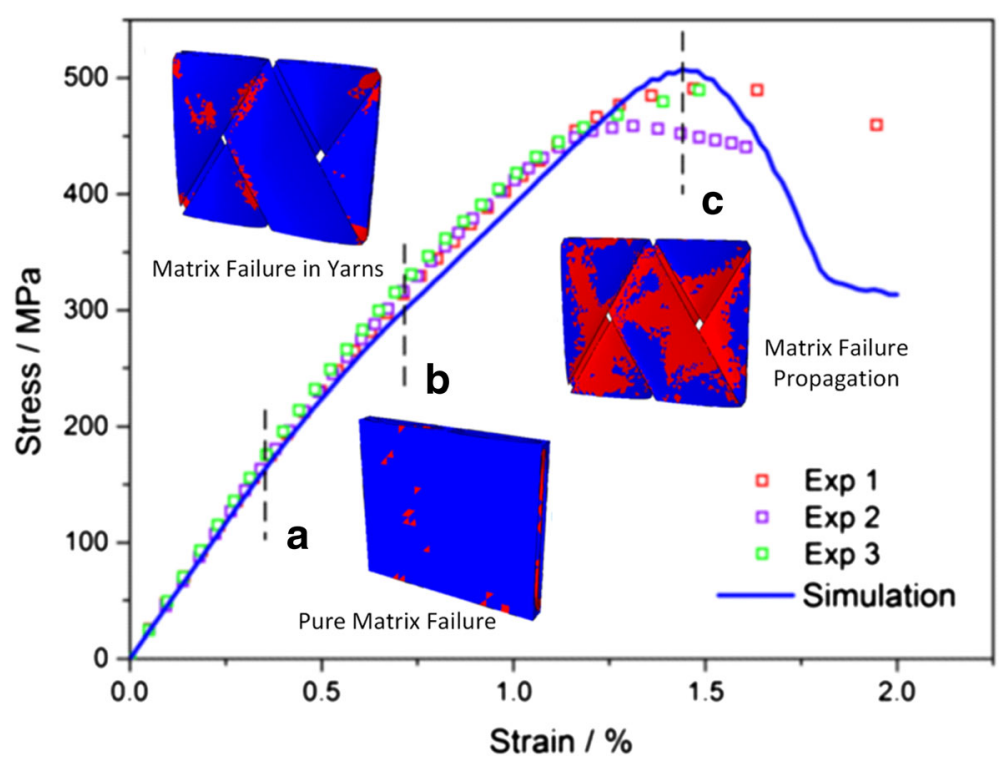

Fig. 5 Predicted stress-strain curve of bi-axial braided composites and damage contours (Wang et al. 2016a)

$$
\begin{aligned}
& X_{e q}^{I i}=\frac{X_{e q}^{I}}{\sqrt{\varnothing_{I}}}, \\
& X_{e q}^{I f}=\frac{2 G_{I}}{\sigma_{e q}^{I i}} .
\end{aligned}
$$

Here, $\varnothing_{I}$ is the value of damage-initiation criteria. $G_{I}$ and $\sigma_{e q}^{I i}$ are the fracture energy density and the initiation damage equivalent stress of failure mode $I$, respectively. The initiation equivalent stress $\sigma_{e q}^{I i}$ could be calculated from the following equation:

$$
\sigma_{e q}^{I i}=\frac{\sigma_{e q}^{I}}{\sqrt{\varnothing_{I}}}
$$

In Eqs. (21)-(24), the equivalent stress $\sigma_{e q}^{I}$ and the equivalent displacement $X_{e q}^{I}$ associated to different failure

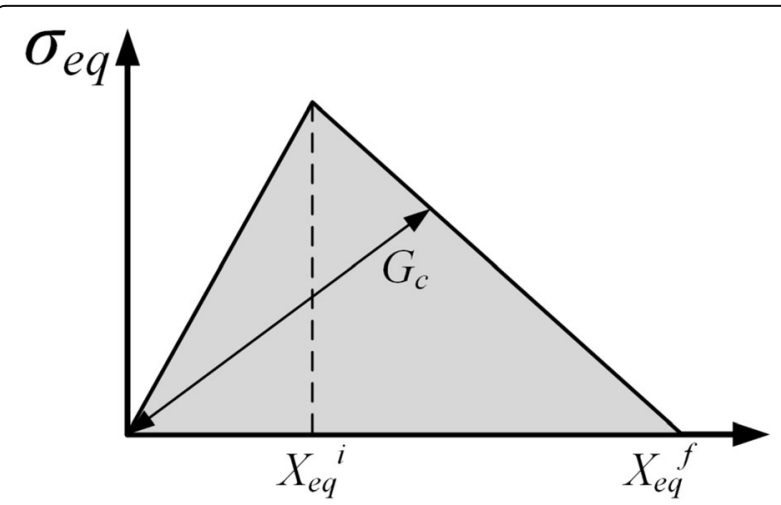

Fig. 6 Linear damage-evolution law in bilinear equivalent stressdisplacement relationship (Li, 2010) modes are expressed in Table 3. The equivalent displacements of damage initiation listed in Table 3 have the similar forms with Eq. (21).

Therefore, the damage-evolution equation is associated with the characteristic element length, local strain and fracture energy of the braided-composite constituents. The damaged stiffness matrix $\boldsymbol{C}(\boldsymbol{D})$ can be expressed in a matrix form by using the components of undamaged stiffness matrix and the principal values of the damage tensor $D_{I}$ according to the Murakami-Ohno damage model (Murakami, 1988).

In the studies conducted by Li et al. (2011), the processes of local damage propagation and failure of braided composites were quantified using the above bilinear damage evolution law. Local failure mechanisms, such as fibre splitting and matrix cracking, were taken into consideration. In a FE model, the braiding architecture of the fibre tows was modelled at meso-scale. Fang and Liang (2011) investigated the compressive properties of $3 \mathrm{D}$ braided composites using this damage theory. The material's damage in damaged stiffness matrix $C(D)$ was computed with three internal DVs that were characterizing fibre, matrix and shear damage $\left(d_{f}, d_{m}\right.$ and $d_{s}$, respectively):

$$
\boldsymbol{C}(\boldsymbol{D})=\frac{1}{\Delta}\left[\begin{array}{ccc}
\left(1-d_{f}\right) E_{1} & \left(1-d_{f}\right)\left(1-d_{m}\right) v_{21} E_{1} & 0 \\
\left(1-d_{f}\right)\left(1-d_{m}\right) v_{12} E_{2} & \left(1-d_{m}\right) E_{2} & 0 \\
0 & 0 & \left(1-d_{s}\right) G_{12}
\end{array}\right],
$$

where $\Delta=1-\left(1-d_{f}\right)\left(1-d_{m}\right) v_{12} v_{21}$. In these studies, only planar stress components were considered, otherwise, a fully three-dimensional damaged stiffness matrix was developed as 


$$
\boldsymbol{C}(\boldsymbol{D})=\Delta^{\prime}\left[\begin{array}{cccccc}
\left(1-d_{m} v_{23} v_{32}\right) d_{f} E_{11} & \left(v_{21}+v_{23} v_{31}\right) d_{f} d_{m} E_{11} & \left(v_{31}+v_{21} v_{32}\right) d_{f} E_{11} & 0 & 0 & 0 \\
& \left(1-d_{f} v_{13} v_{31}\right) d_{m} E_{22} & \left(v_{32}+d_{f} v_{12} v_{31}\right) d_{m} E_{22} & 0 & 0 & 0 \\
& & \left(1-d_{f} d_{m} v_{12} v_{21}\right) E_{33} & 0 & 0 & 0 \\
& \text { sym } & & d_{f} d_{m} G_{12} & 0 & 0 \\
& & & & d_{m} G_{23} & 0 \\
& & & & & d_{f} G_{31}
\end{array}\right],
$$

where $\Delta^{\prime}=1-d_{f} d_{m} v_{12} v_{21}-d_{m} v_{23} v_{32}-d_{f} v_{13} v_{31}-2 d_{f} d_{m} v_{21}$ $v_{32} v_{13}$. Zhang et al. 2014, 2015a, b) applied such 3D damaged stiffness matrix with the mentioned equivalent stress and displacement relationship to investigate the contribution of local details of the braiding architecture and the local stresses, strains, and damage mechanisms on the global response of braided composites. In Zhang's studies, a fully three-dimensional FE model was developed, with periodic boundary conditions applied along the gauge section length, and free boundary conditions applied at the two free edges of the model of the experimental coupon. The model also showed the capability of predicting a free-edge effect besides the primary damage evolution in tri-axial braided composites, as shown in Fig. 7.

Zhou et al. (2013) implemented a two-step, multi-scale progressive-damage analysis to study damage and failure behaviours of 2D plain weave composites under various uniaxial and biaxial loading conditions. In this model, a similar bilinear damage evolution approach (Zako et al. 2003) with a formal-unified 3D Hashin-type criterion were employed to facilitate analysis and engineering applications, with shear nonlinearity considered in the stiffness matrix of yarn. The results showed that tensile strength decreased for off-axis angles (see Fig. 8). In the Zhou's study, the damaged stiffness matrix could be presented explicitly as follows:

$$
C(D)=\left[\begin{array}{cccccc}
b_{L}^{2} C_{11} & b_{L} b_{T} C_{12} & b_{L} b_{Z} C_{13} & 0 & 0 & 0 \\
& b_{T}^{2} C_{22} & b_{T} b_{Z} C_{23} & 0 & 0 & 0 \\
& & b_{Z}^{2} C_{33} & 0 & 0 & 0 \\
& & & b_{L T} C_{44} & 0 & 0 \\
& & & & b_{T Z} C_{55} & 0 \\
& & & & & b_{Z L} C_{66}
\end{array}\right],
$$

where $\quad b_{L}=1-D_{L}, \quad b_{T}=1-D_{T}, \quad b_{Z}=1-D_{Z}$, $b_{L T}=\left(\frac{2\left(1-D_{L}\right)\left(1-D_{T}\right)}{2-D_{L}-D_{T}}\right)^{2}, b_{T Z}=\left(\frac{2\left(1-D_{T}\right)\left(1-D_{Z}\right)}{2-D_{T}-D_{Z}}\right)^{2}, b_{Z L}=\left(\frac{2\left(1-D_{Z}\right)\left(1-D_{L}\right)}{2-D_{Z}-D_{L}}\right)^{2}$. $C_{i j}(i, j=1,2,3)$ are the components of the undamaged stiffness matrix, $D_{L}, D_{T}$ and $D_{Z}$ are the DVs in longitudinal, transverse and thickness directions, respectively, based on Eq. (21). Such a scheme was also applied by Zhang et al. (2015a) to study meso-scale progressive damage of 3D five-directional braided composites under transverse compression.

The linear damage-evolution method was also adopted by Matveev et al. (2014) combined with a voxel mesh technique to analyse variability of fibre strength numerically from micro to macro-scale taking into account the size effect and transitions between the scales. The multiscale approach demonstrated that a wide distribution of fibre strength led to a narrow distribution of composite strength accompanied a shift to lower mean values.

Another multi-scale approach for PFA of braided composites at coupon-level was elaborated and validated by $\mathrm{Xu}$ et al. (2015a, b). Starting from elastic constants of constituents (i.e. fibre and matrix), ply-level effective material properties were predicted using a micro-mechanical unitcell model, with ply's effective properties assigned to each tow in a meso-mechanical model of braided composites. In their study, the damage evolution was determined by the equivalent strain, a scalar measure of the strain components. Using the equivalent strain and equivalent stress, a multi-linear stress-strain damage model was proposed for the matrix in fibre tows, as illustrated in Fig. 9.

As shown in Fig. 9, the mechanical response of yarns followed the linear stress-strain relation before damage occurred in the matrix. After this, the material exhibited

\begin{tabular}{|c|c|c|}
\hline Failure mode I & Equivalent displacement & Equivalent stress \\
\hline$L_{t}, \sigma_{1} \geq 0$ & $X_{e q}^{L t}=I \sqrt{\left\langle\varepsilon_{11}\right\rangle^{2}+\varepsilon_{12}^{2}+a \varepsilon_{31}^{2}}$ & $I\left(<\sigma_{11}><\varepsilon_{11}>+\sigma_{12} \varepsilon_{12}+a \sigma_{13} \varepsilon_{13}\right) / X_{e q}^{L t}$ \\
\hline$L_{c} \sigma_{1}<0$ & $X_{e q}^{L C}=\mid\left\langle-\varepsilon_{11}\right\rangle$ & $I\left(<-\sigma_{11}><-\varepsilon_{11}>\right) / X_{e q}^{L C}$ \\
\hline$Y_{\mathrm{t}}, \sigma_{2} \geq 0$ & $X_{e q}^{Y t}=\mid \sqrt{\left\langle\varepsilon_{22}\right\rangle^{2}+\varepsilon_{12}^{2}+a \varepsilon_{23}^{2}}$ & $I\left(<\sigma_{22}><\varepsilon_{22}>+\sigma_{12} \varepsilon_{12}+a \sigma_{23} \varepsilon_{23}\right) / X_{e q}^{Y t}$ \\
\hline$Y_{c}, \sigma_{2}<0$ & $\left.X_{e q}^{Y c}=1<-\varepsilon_{22}\right\rangle$ & $I\left(<-\sigma_{22}><-\varepsilon_{22}>\right) / X_{e q}^{Y c}$ \\
\hline$Z_{\mathrm{t},} \sigma_{3} \geq 0$ & $X_{e q}^{Z t}=1 \sqrt{\left\langle\varepsilon_{33}\right\rangle^{2}+\varepsilon_{23}^{2}+\varepsilon_{31}^{2}}$ & $I\left(<\sigma_{33}><\varepsilon_{33}>+\sigma_{23} \varepsilon_{23}+\sigma_{13} \varepsilon_{13}\right) / X_{e q}^{Z t}$ \\
\hline$Z_{c}, \sigma_{3}<0$ & $\left.X_{e q}^{Z c}=1<-\varepsilon_{33}\right\rangle$ & $I\left(<-\sigma_{33}><-\varepsilon_{33}>\right) / X_{e q}^{Z c}$ \\
\hline$<x>=(x+|x|) / 2$ & & \\
\hline
\end{tabular}

Table 3 Equivalent displacements and stresses corresponding to different failure modes 


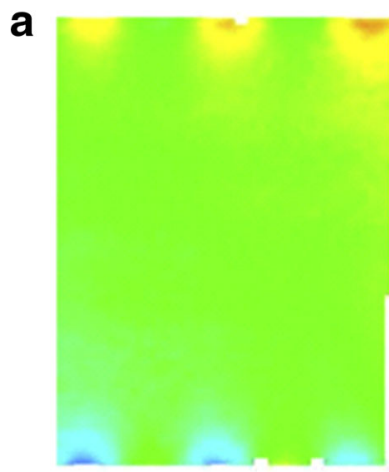

Global Strain $0.4 \%$

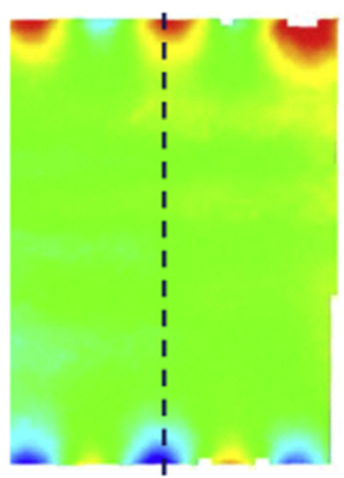

Moment before Failure
Out-of-plane

Displacement

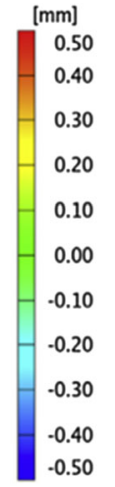

b
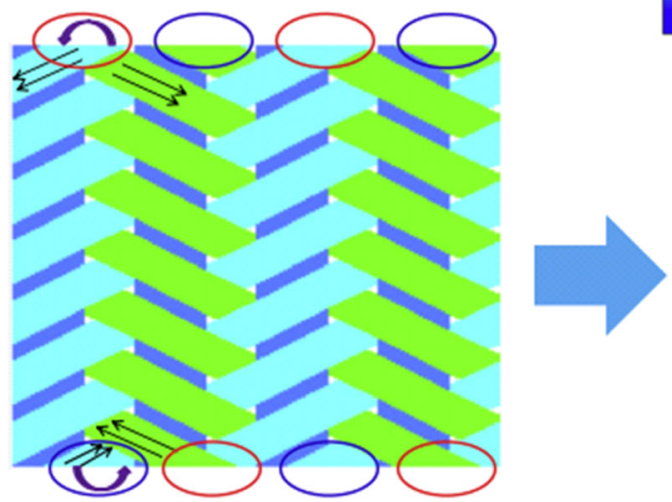

Fig. 7 Free-edge warping behaviour: a out-of-plane displacement; b scheme of warping locations and directions (Zhang et al. 2015a, b)

hardening behaviour followed by softening, depending on the damage state. In order to predict the strength, mesoscale FE models of representative unit cells of bi- and triaxial braided composites were developed (Xu et al. 2015a, b). Another example was presented by Zhao et al. (2016) to bypass the complexity associated with meso- and

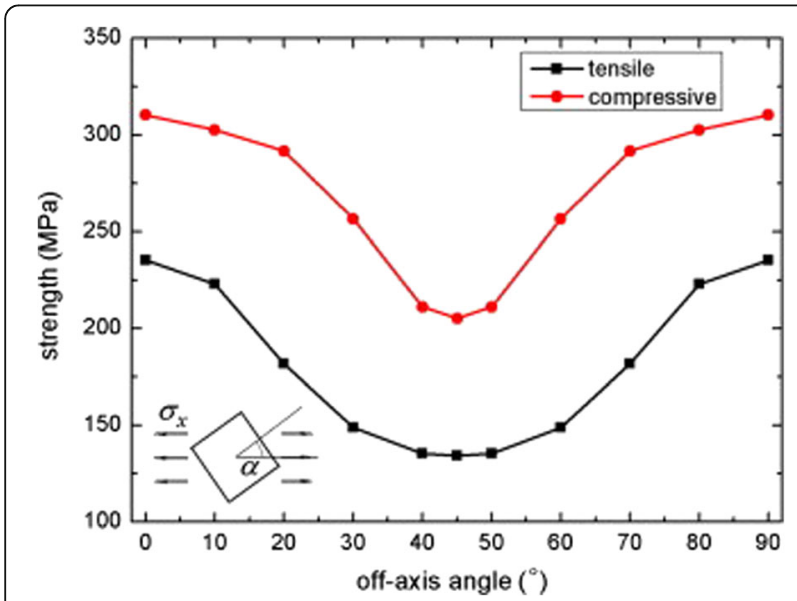

Fig. 8 Strength of woven composites for different off-axis angles (Zhou et al. 2013) micro-mechanics. They proposed simplified methods for progressive-failure prediction in braided composites mainly subjected to uniaxial in-plane loading and bending. The global stress-strain behaviour and principle damage modes in bending were obtained without losing much accuracy.

Apparently, most schemes were based on linear damage models. A non-linear damage evolution approach

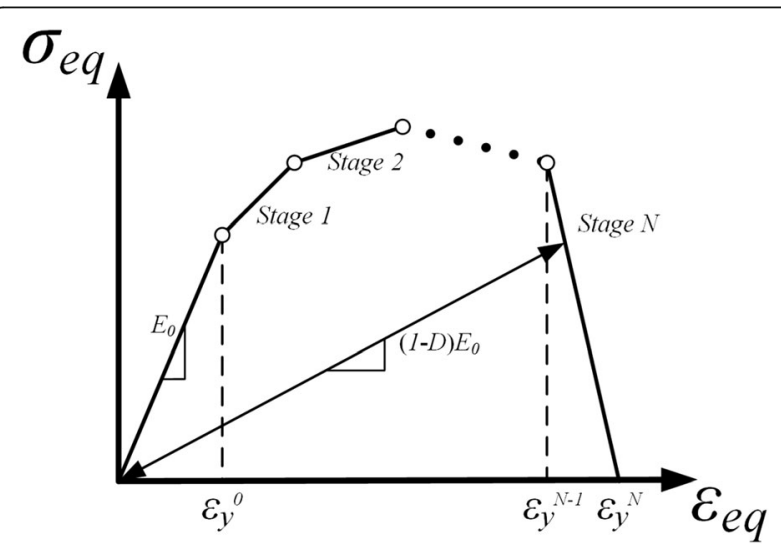

Fig. 9 Multi-linear stress-strain damage model (Xu et al. 2015a, b) 
was first proposed by Maimí et al. (2007) to regularize the energy dissipated at a material point by each failure mechanism. A viscous model is usually applied to mitigate the convergence difficulties associated with strainsoftening constitutive models. Therefore, the non-linear damage evolution law is usually presented as an exponential expression in the following general form:

$$
d_{i}=1-\frac{1}{f\left(r_{i}\right)} \exp \left[A_{i}\left(1-f\left(r_{i}\right)\right)\right]
$$

where the subscript $i$ denotes different damage modes, $d_{i}, f\left(r_{i}\right), A_{i}$ and $r_{i}$ are the DV, the damage-activation function, the coefficient and the damage threshold value, respectively. In recent investigations, the non-linear damage evolution approach was applied to capture progressive damage evolution in braided composites in static and quasi-static loading regimes.

$\mathrm{Lu}$ et al. (2013) determined a set of reasonable interfacial properties for predicting a mechanical response of 3D braided composites under uniaxial tension and investigated the effect of interfacial properties on their stressstrain behaviour. In their numerical model, a 3D Linde failure criterion was adopted to describe a progressivedamage process in yarns, which was a strain-based continuum damage formulation with different failure criteria for fibre and matrix failure modes, respectively. A gradual degradation of the material properties was assumed, which was controlled by the individual fracture energies of fibre and matrix. Failure occurred once effective strain $f\left(\varepsilon_{i}\right)$ exceeded its threshold strain value $\varepsilon_{i f, t}$. DVs for fibre $\left(d_{f}\right)$ and matrix $\left(d_{m}\right)$ modes were defined as follows:

$$
d_{f}=1-\frac{\varepsilon_{L}^{f, t}}{f\left(\varepsilon_{L}\right)} \exp \left[-C_{11} \varepsilon_{L}^{f, t}\left(f\left(\varepsilon_{L}\right)-\varepsilon_{L}^{f, t}\right) \frac{L^{*}}{G_{f}}\right],
$$

and

$$
d_{m}=1-\frac{\varepsilon_{T}^{f, t}}{f\left(\varepsilon_{T}\right)} \exp \left[-C_{22} \varepsilon_{T}^{f, t}\left(f\left(\varepsilon_{T}\right)-\varepsilon_{T}^{f, t}\right) \frac{L^{*}}{G_{m}}\right],
$$

where $G_{f}$ and $G_{m}$ are the fracture energy of the fibre and matrix while $L^{*}$ is the characteristic length related to the elements. After failure initiation, the damaged stiffness matrix could be defined as where $d_{m 1}$ and $d_{m 2}$ are two components of $d_{m}$ in different defined directions. To improve the convergence of nonlinear numerical calculations, a Duvaut-Lions viscous model (Duvaut and Lions 2012) was implemented in UMAT. Therefore, the DVs $d_{i}$ could be regularized as:

$$
\dot{D_{i}}=\frac{1}{\eta}\left(d_{i}-D_{i}\right)
$$

Here, $\eta$ is the viscous parameter and $D_{i}$ is the regularized DV for each failure mode. Computing with this damage-evolution approach, the tensile modulus and strength of 3D braided composites were obtained with a good agreement to the experimental data. The calculated results showed that the effect of interfacial elastic modulus on the tensile modulus of 3D braided composites was prominent, while the strength of braided composites was not very sensitive to that parameter, as shown in Fig. 10.

Zhong et al. (2015) further developed the above mentioned exponential evolution approach for failure analysis of 3D woven composites under tension. Except for the longitudinal tension failure modes, the exponential damage evolution laws were still adopted for the fibre yarn in the model. Meanwhile, the linear and exponential damage evolution laws were used to represent the phenomena of fibre bridging and fibre pull-out in a fibre yarn (Bazant and Planas, 1997; Maimí et al. 2007), as shown in Fig. 11. The Puck failure criteria (Puck et al. 2002) were adopted for the fibre yarn as it could predict not only location but also orientation of a crack.

The damage process was irreversible, and the mechanical properties degraded as soon as any criterion was activated. The DVs of the fibre yarn could be expressed as

$$
d_{1 t}=1-\frac{1-d_{1 t}^{l}}{r_{1 t}^{e}} \exp \left[A_{1 t}\left(1-r_{1 t}^{e}\right)\right]
$$

and

$$
\begin{aligned}
d_{N} & =1-\frac{1}{r_{N}} \exp \left[A_{N}\left(1-r_{N}\right)\right], N \\
& =\{1 c, 2 t, 2 c, 3 t, 3 c\},
\end{aligned}
$$

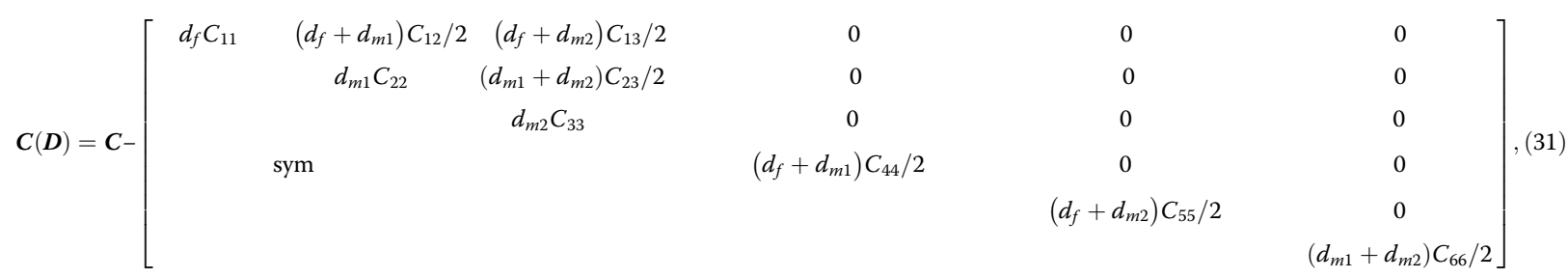




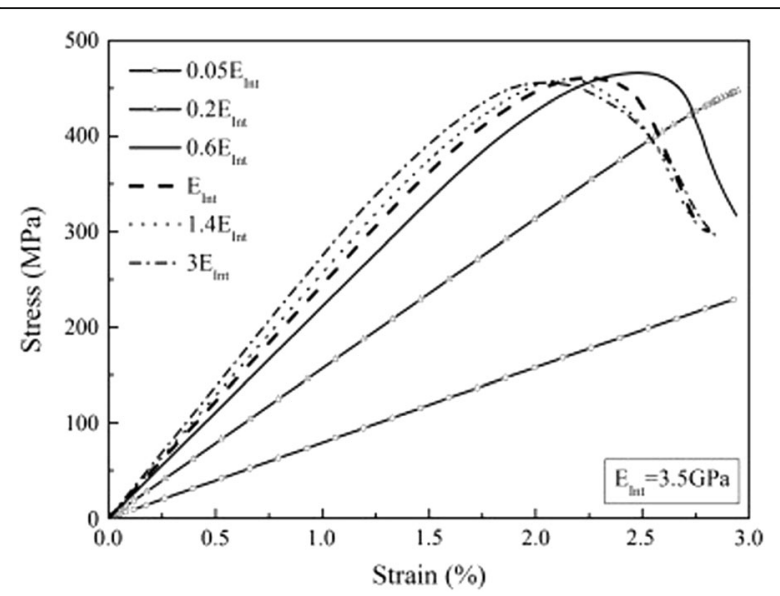

Fig. 10 Effect of interfacial elastic modulus on stress-strain curves of 3D braided composites (Lu et al. 2013)

where $A_{N}$ is the parameter that defines the exponential softening law. $r_{1 t}^{e}, A_{1 t}$ and $d_{1 t}^{l}$ are the auxiliary damage threshold parameter, the softening-law parameter and the DV for the longitudinal failure mode in tension, respectively. These parameters were defined by other material-property inputs. The DVs $d_{4}$ and $d_{6}$ represent the effect of damage on shear stiffness due to fibre and inter-fibre fracture, and $d_{5}$ due to interfibre fracture. So, the DVs $d_{4}, d_{6}$ and $d_{5}$ could be given by:

$$
\begin{aligned}
& \left.d_{4}=1-\left(1-d_{1}\right)\left(1-d_{2}\right)\right], \\
& \left.d_{6}=1-\left(1-d_{3}\right)\left(1-d_{1}\right)\right],
\end{aligned}
$$

and

$$
\left.d_{5}=1-\left(1-d_{2}\right)\left(1-d_{3}\right)\right]
$$

Accordingly, $S(d)$ is the damaged compliance matrix of fibre yarns, which could be written as:

$$
\boldsymbol{S}(\boldsymbol{d})=\left[\begin{array}{cccccc}
\frac{1}{\left(1-d_{1}\right) E_{11}} & -\frac{v_{12}}{E_{11}} & -\frac{v_{13}}{E_{11}} & 0 & 0 & 0 \\
& \frac{1}{\left(1-d_{2}\right) E_{22}} & -\frac{v_{23}}{E_{22}} & 0 & 0 & 0 \\
& & \frac{1}{\left(1-d_{3}\right) E_{33}} & 0 & 0 & 0 \\
& & & \frac{1}{\left(1-d_{4}\right) G_{12}} & 0 & 0 \\
& & & & \frac{1}{\left(1-d_{5}\right) G_{23}} & 0 \\
& & & & & \frac{1}{\left(1-d_{6}\right) G_{31}}
\end{array}\right] .
$$

The failure modes of the matrix are different from those of the fibre yarn. However, the exponential evolution law could also be adopted based on mechanical response of the matrix material. Using this method, as seen in Fig. 12, the predictions of failure of woven composites under tension agreed well with the corresponding experiments (Zhong et al. 2015). The obtained results showed that mechanical properties of 3D woven composites were influenced by their thickness. The slope of stress-strain curve and the failure strength increased with the thickness growing.

\section{Other advanced studies of progressive failure}

Although complexities of modelling mechanical behaviour of braided composites are present in many aspects, the improvement of modelling techniques is generally driven by two purposes. One is to account for all the physical phenomena observed in experiments in $\mathrm{FE}$ modelling; the other is to resolve numerical limitations of the FE method and balance its efficiency and accuracy.

Recently, nonlinear problems of mechanics of textile composites were considered in many studies. In experimental observations, two reasons of nonlinearities can be identified: a geometrical nonlinearity caused by a fabric structure and a material nonlinearity caused by micro-cracks evolving in the material inducing a loss of stiffness, indicating that the nonlinearity is related to progressive failure of the material. As mentioned above, the CDM approach generally uses a damage parameter
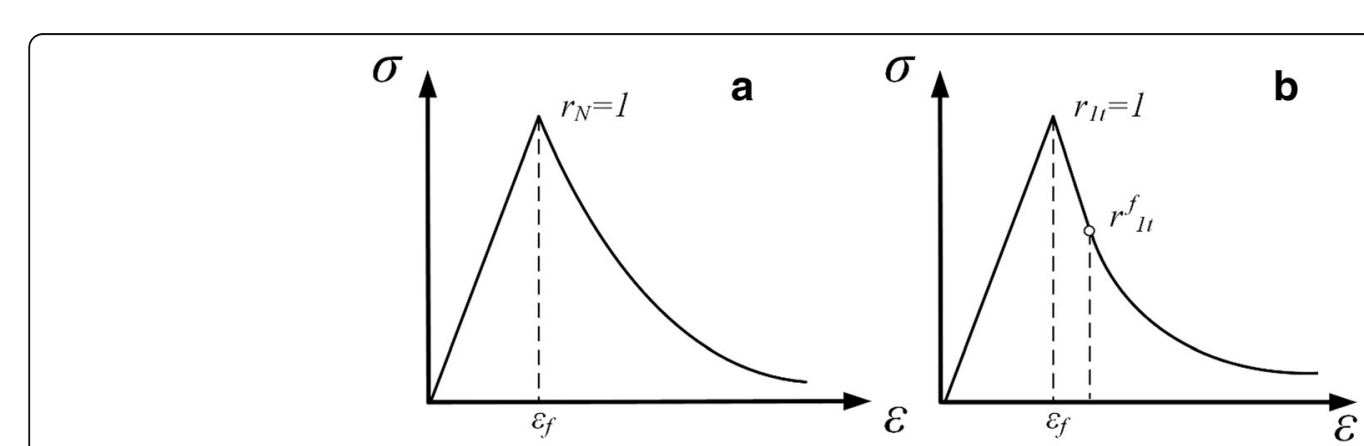

Fig. 11 a Exponential damage evolution law for fibre yarn; b linear and exponential laws for fibre failure mode in tension (Zhong et al. 2015) 


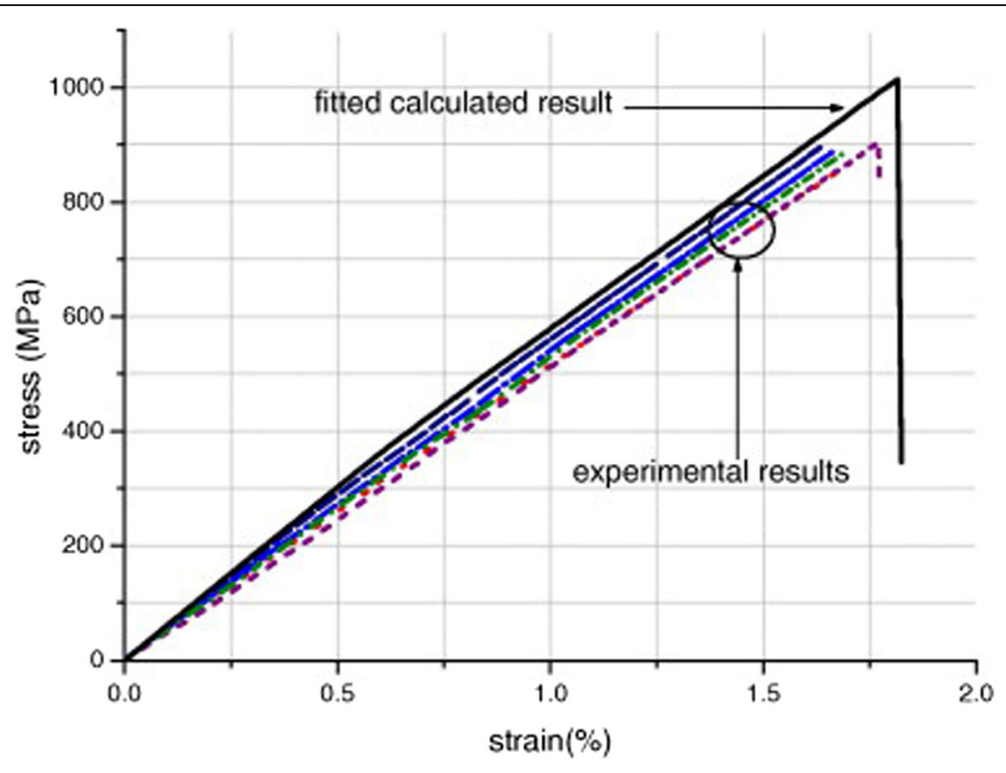

Fig. 12 Predicted stress-strain curves of woven composites and experimental results (Zhong et al. 2015)

characterizing the damage evolution responsible for the loss of stiffness due to micro-cracks. Besides, the nonlinearity can be considered as macroscopic behaviour of the material independently from damage evolution.

Cousigné et al. (2013) developed a nonlinear numerical material model for textile composite materials considering post-failure damage. The nonlinearity was represented by the Ramberg-Osgood formulation. This formulation was developed by Bogetti et al. (2004) to estimate an equivalent stress function corresponding to an equivalent strain state:

$$
\sigma=\frac{E \varepsilon}{\left(1+\left(\frac{E \varepsilon}{\sigma_{a}}\right)^{n}\right)^{\frac{1}{n}}}
$$

where $\sigma_{a}$ is the asymptotic stress level and $n$ is the shape parameter. The nonlinear behaviour was linked to a unidimensional plasticity definition to account for permanent deformation without coupling between different material directions. Failure was predicted using the maximum-stress or Tsai-Wu failure criterion. A smeared formulation involving DVs was used to avoid undesirable localization phenomena (Pinho et al. 2006). In this study, the model represented nonlinear material behaviour very well; a good agreement between experimental and numerical results was obtained under tensile and compressive loadings. However, the permanent deformation was still too high and stiffness degradation for the unloading process should be developed.

With development of the multi-scale modelling approach, another key problem for improving the accuracy of FE simulations is a link between micro- and meso- scale models. In a multi-scale approach, micro- and mesoscale models are usually carried out subsequently. Outputs of the microscopic model, including effective material properties of yarns, are commonly regarded as inputs for the meso-scale model (Šmilauer et al. 2011). In some studies (Xu et al. 2015a, b; Mao et al. 2013), a correlation between mesoscale tow stresses and microscale constituent stresses was established with the concept of a stress amplification factor (SAF). The correlation can be expressed by the following formula:

$$
\sigma_{i}=M_{i} \bar{\sigma}+A_{i} \Delta T
$$

where $\bar{\sigma}$ and $\sigma_{i}$ are the mesoscopic stresses and the microscopic stresses in fibres or matrix. The SAFs for the meso stress $M_{i}$ and for the temperature increment $A_{i}$ were determined by means of direct finite-element analysis of a micro-scale unit cell with proper boundary conditions. Similarly, Schultz and Garnich (2013) proposed a multicontinuum technology (MCT) and successfully predicted the initial matrix failure of a $0^{\circ} / \pm 45^{\circ}$ tri-axially braided composite. The MCT provided a way to link the results provided by the meso-scale and macro-scale models with a good computational efficiency. In this approach, constituent properties were used to obtain composite properties employing a micromechanical model. Then, an analytical relationship between composite stresses and strains and those in constituents was obtained based on an assumption that a continuum field existed for each constituent. This study also demonstrated capability of predicting initial matrix failure in textile composites with $n$ constituent based on extension of the MCT. 
Moreover, both micro- and meso-scale models can be developed with the GMC method. A comparison of meso- and micro-scale approaches to modelling progressive damage in plain-weave-reinforced polymer-matrix composites was carried out by Bednarcyk et al. (2015). As illustrated in Fig. 13, the meso-scale approach treated the woven composite tows as effective materials, utilizing an anisotropic continuum damage model. The micro-scale approach utilized the GMC semi-analytical micromechanical theory to represent a nonlinear response of the tows. The same damage model was used to model the matrix material within the tows. FE predictions were made for the shear and tensile responses of the plain-weave composite. Very similar results were obtained using the two approaches, for both effective behaviour of the woven composites and local damage fields predicted. For example, in the tensile simulations, both approaches predicted similar additional local damage coupling in the tow cross-over regions due to the multi-axiality of the stress fields. However, the FE results were considerably mesh-dependent because of softening present in the damage model. This mesh-dependence could be reduced with a crack-band approach, which regularized the energy dissipated in the damage model.

Recently, more advanced studies of mechanical properties of 3D braided composites were considered to include some microscopic effects, such as defects. Dong and Huo (2016) developed a two-scale FE model for fibre tows and 3D braided composites to predict their elastic properties and micro stresses. Two basic types of defects - voids in a resin matrix and dry patches in fibre tows -were taken into account. The obtained results showed that the volume fraction of voids in fibre tows had a more notable effect on the elastic constants than those of the matrix. The longitudinal Poisson's ratios increased with increasing volume fraction of voids, proving that presence of defects promoted transverse deformation in $3 \mathrm{D}$ braided composites under longitudinal loading. However, the effect of internal defects on the strength was not included.
Döbrich et al. (2016) paid attention to a micro-scale character of a reinforcing textile in their study of a meso-scale RUC; this is not common due to higher computational efforts compared with multi-scale approaches. In this study, a digital element approach was used to model the textile structure with a near micro-scale resolution for the purpose of reinforcement analysis. The textile unit-cell generation method enabled a process-dependent modelling and, therefore, textile-specific simulations of composites with excellent agreement with real manufactured samples. Convergence analyses were carried out, and the textile model was directly used to build up a virtual composite model suitable for virtual mechanical tests, as illustrated in Fig. 14. A comparison of simulation results and test data demonstrated their very good agreement. The introduced model had a capability to be a part of a complete virtual process chain for development of high-performance composites.

To summarise, FE-based methods showed their capabilities and advantages in predicting the mechanical response of woven and braided composites. Numerous failure criteria and damage-evolution laws can be effectively applied in models of braided composite. Based on the above discussions, the main purpose of recent studies was to improve simulation accuracy, which depends on two important considerations. The first one is that various failure modes observed in experiments should be accounted for in the FE simulations. The other is that advanced analytical approaches should be carried out to connect scales in multi-scale models. However, taking these considerations inevitably reduces the computational efficiency. Although some modelling attempts showed good accuracy when compared with experimental results, usually they were only demonstrated for a single structure or applicable only to some specific cases. More studies are needed to analyse the effect of braiding parameters, boundary conditions and complicated loading conditions in the future.
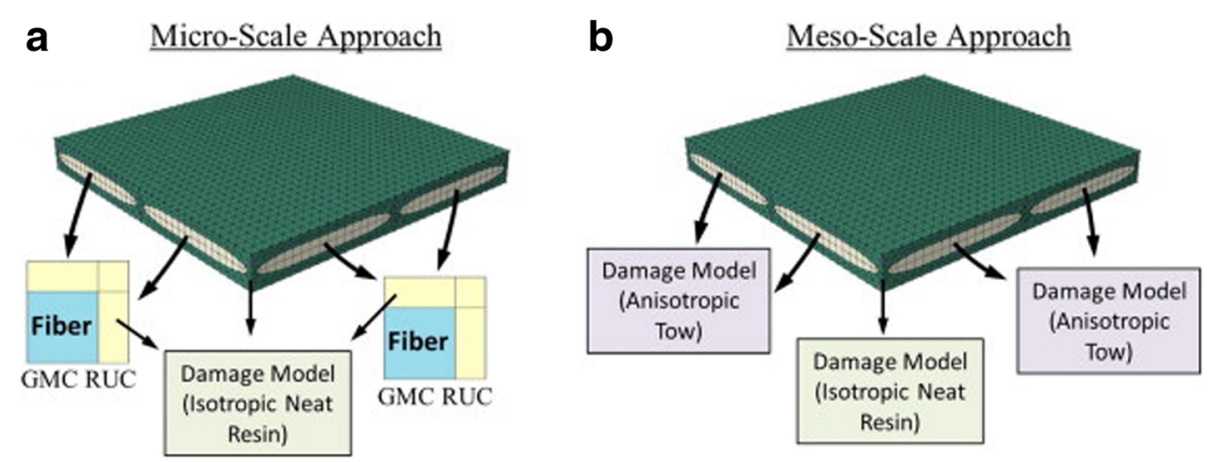

Fig. 13 Schematic of micro-scale (a) and meso-scale (b) approaches to model plain-weave composite using GMC micromechanics model with repeating unit cell (Bednarcyk et al. 2015) 


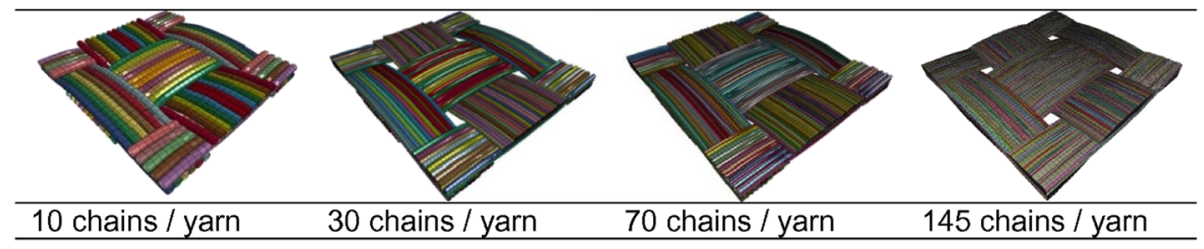

Fig. 14 Different convergence levels applied in Döbrich et al. (2016)

\section{Modelling impact behaviour of braided composites}

During manufacturing, service life-time, maintenance etc., braided composites are often subjected to various dynamic loading conditions, from low-velocity impacts to ballistic loads. In such regimes, small weak point in a composite part can lead to catastrophic consequences. Therefore, a response of braided composites to such conditions should be clearly understood. An overview of general impact behaviour of fibre-reinforced polymeric composites (FRPC) is given in some review papers (Davies and Olsson 2004; Crookston et al. 2005; Dixit and Harlal 2013). In most studies, the composites were impacted at different velocities, and the resulting damage was evaluated. The effects of various parameters such as impact energy and impactor shape on impact responses of composites were also studied. However, little attention was paid to braided composites. Impact damage in structural textile composites was introduced into consideration recently (Binienda, 2012; Ma and Gao, 2013), and most of these efforts were based on experimental studies, rather than numerical simulations. This section introduces some recent numerical attempts to predict damage in braided composites under impact loadings, with impact energy from relatively low levels to high ones.

\section{Modelling low-velocity impact of braided composites}

In a low-velocity impact (LVI), contact duration between an impactor and a target is long enough for entire structure to respond and, hence, absorb more elastic energy. Low-velocity impacts with sufficient energy can cause various types of barely visible impact damage (BVID), such as matrix failure, delamination, fibre breakage, fibre-matrix debonding and fibre pull-out. The CDM approach was investigated extensively in recent years and its application to impact-damage modelling proved to be very effective for UD laminates. Compared with laminates, few authors focused on a LVI response of woven and braided composites. LVIs are commonly encountered in personal sports protection and some other structural fortifications.

The maximum-stress criterion with the instantaneous stiffness-degradation method was successfully used in modelling LVIs in braided composites. Sun et al. (2013) studied low-velocity impact properties of four-step 3D braided composites suffering a drop-weight impact with velocity ranging from $1 \mathrm{~m} / \mathrm{s}$ to $6 \mathrm{~m} / \mathrm{s}$. In this FE-based approach, impact damage was determined by maximumstress criteria in several failure modes. In addition, the Critical Damage Area (CDA) theory introduced by Rosen (1964) and Hahn (1973) was also employed. The CDA is governed by a composite's interaction length, which can be as low as $1 \mathrm{~mm}$ for tape-based composites and up to $100 \mathrm{~mm}$ for some 3D interlock weaves (Cox et al. 1996). According to the CDA theory, a critical damage length $(\delta)$ is defined as:

$$
\delta=4 \gamma_{f}\left(\frac{X_{f}}{4 \tau_{m}}\right)^{\frac{\kappa}{\kappa+1}}\left[\frac{(\kappa+1) L}{2 \gamma_{f}}\right]^{\frac{1}{\kappa+1}}
$$

where $\gamma_{f}$ is the fibre-tow radius, $X_{f}$ is the average tension strength of fibres, $L$ is the tow length, typically assumed 1 unit length, $\tau_{m}$ is the matrix yield stress, and $\kappa$ is the Weibull parameter, assumed to be 7.6. By definition, the critical damage area is $\delta^{2}$. As the damage area increases, the modulus of the fibre tows degrades as

$$
E^{i}=E_{0}^{i}\left[1-\left(\frac{D A-D A_{f}^{i}}{C D A}\right)^{2}\right],
$$

where $E^{i}$ is the $E_{11}$ Young's Modulus at point $i . E_{0}^{i}$ is the undamaged modulus. $C D A$ is the critical damage area. $D A$ is the area, where the value of longitudinal stress exceeds the tension strength of the composite $X_{T}$, and $D A_{f}^{i}$ is the value of $D A$ when point $i$ exceeds its maximum stress. $D A$ is the next status of $D A_{f}^{i}$.

The instantaneous stiffness degradation scheme is shown in Table 4. The user-defined subroutine VUMAT is usually used to define the mechanical constitutive relationship of the 3D braided composite under dropweight impact. VUMAT also works on failure assessment and updates stress in ABAQUS. In the Sun's work, model predictions of a load-displacement curve, a peak force and energy corresponding to the peak force were in a reasonable agreement with experimental results. The damage morphologies of 3D braided composite specimens showed that the main failure mode was resin cracks, debonding and fibre-tow breakage.

This method was also used to investigate drop-weight loading of three-dimensional angle-interlock woven glass 
Table 4 Failure criteria and degradation character according to Sun et al. (2013)

\begin{tabular}{lll}
\hline Failure & Criteria & Degradation \\
\hline Tension along 1-direction & $\sigma_{11}^{\top}>X_{T} ; C D A_{1}>C D A$ & $E_{11}=0, G_{12}=0, G_{13}=0$ \\
Compression along 1-direction & $\sigma_{11}^{C}<X_{C}$ & $E_{11}=0.95 E_{11}, \sigma_{11}^{C}=X_{C}$ \\
Tension along 2-direction & $\sigma_{22}^{\top}>Y_{T}$ & $E_{22}=0, G_{12}=0, G_{13}=0$ \\
Compression along 2-direction & $\sigma_{22}^{C}<Y_{C}$ & $\sigma_{22}^{C}=Y_{C}$ \\
Tension along 3-direction & $\sigma_{33}^{\top}>Y_{T}$ & $E_{33}=0, G_{13}=0, G_{23}=0$ \\
Compression along 3-direction & $\sigma_{33}^{C}<Y_{C}$ & $\sigma_{33}^{C}=Y_{C}$ \\
Shear in 2-3 plane & $\sigma_{23}^{S}>S S_{23}$ & $G_{23}=0$ \\
Shear in 1-2 plane & $\sigma_{12}^{S}>S S_{12}$ & $G_{12}=0$ \\
Shear in 1-3 plane & $\sigma_{13}^{S}>S S_{13}$ & $G_{13}=0$
\end{tabular}

fibre/unsaturated polyester resin composites with a conical impactor (Sun et al. 2012a, b). The corresponding load-displacement histories and failure modes were obtained from numerical simulation and verified by experimental results. It was observed that as the impact energy increased, both the maximum impact load and deflection also increased. Sevkat et al. (2009a, b) adopted a very similar approach to simulate drop-weight tests of hybrid plain-woven glass-graphite fibres/toughened epoxy composites with commercial 3D dynamic nonlinear FE software, LS-DYNA. Evolution of dynamic force, strain and absorbed energy as well as post-impact damage patterns obtained from experiments and FE simulations were in a good agreement. Colombo and Vergani (2016) characterized a textile carbon-fibre-reinforced composite in undamaged and damaged conditions, with numerical and analytical micromechanical approaches, in order to provide a method for assessing its residual stiffness after impact. An extent of degradation of the damaged composite was estimated by Blackketter-type reduction factors applied to elastic properties of unit cells. The results showed that the values of the experimental in-plane residual stiffness in the damaged region decreased to $46 \%$ of its initial value. With this simple general approach, it was possible to predict a range of stiffness reduction for braided composites. However, in these studies, neither progressive damage nor plastic effect was accounted for in the FE models. Besides, values of the maximum impact displacement and interface delamination were not well captured. Usually, such approaches do not aim to run explicit simulations of the impact.

Continuous stiffness degradation associated with the Hashin failure criteria was also applied to dynamic problems. Since this approach may lead to excessive element distortions and other related numerical difficulties, element deletion was utilised in simulation. Gideon et al. (2015) investigated a response of plain-woven basaltunsaturated polyester composites to low-velocity impact both experimentally and with FE method simulations. Schwab et al. (2016) studied a carbon fabric/epoxy system. In these studies, damage and failure behaviours of the textile composites was modelled using an orthotropic energy-based CDM approach, with DVs depending on an equivalent stress-displacement relationship, as presented in Section 2.2; while delamination between layers was simulated with an interface cohesive-zone model. The simulations showed that a stress distribution during the impact event depended mostly on the reinforcing phase of the laminates. The behaviour of composites under low-velocity impact was defined mainly by the initial impact energy, rather than impact velocity or impactor mass. The proposed modelling strategy provided the ability to predict the overall energy absorption of a composite subjected to a transverse impact as well as energy contributions of individual mechanisms. Furthermore, shell elements were applied in these models to increase computational efficiency and stability. Hence, these approaches were suitable to simulate complete perforation of the composite, as shown in Fig. 15. However, damage and failure within shell elements representing individual plies resulted from in-plane stress and strain components only. Therefore, damage due to transverse shear and out-ofplane tension was not accounted for. A comparative study was carried out by Wang et al. (2017a, Mater Des, under review) applying three-dimensional continuum and shell elements to explore the effect of through-thickness failure modes on energy absorption of the composite. In this study, a multi-scale computational approach was developed and the 3D Hashin damage criteria were applied to capture main damage modes of a braided textile composite. The results show that both surface- and elementbased CZM can be applied as interface between composite layers. When shell elements were used as composite plies, the absorbed energy was underestimated. The progressive failure model with 3D stress elements provided more precise results for the delamination areas and energy dissipation capacity, at a higher computational cost.

In most of the modelling studies, the applied strategies provided a good representation at a homogeneous level, but could not represent the local damage modes related 


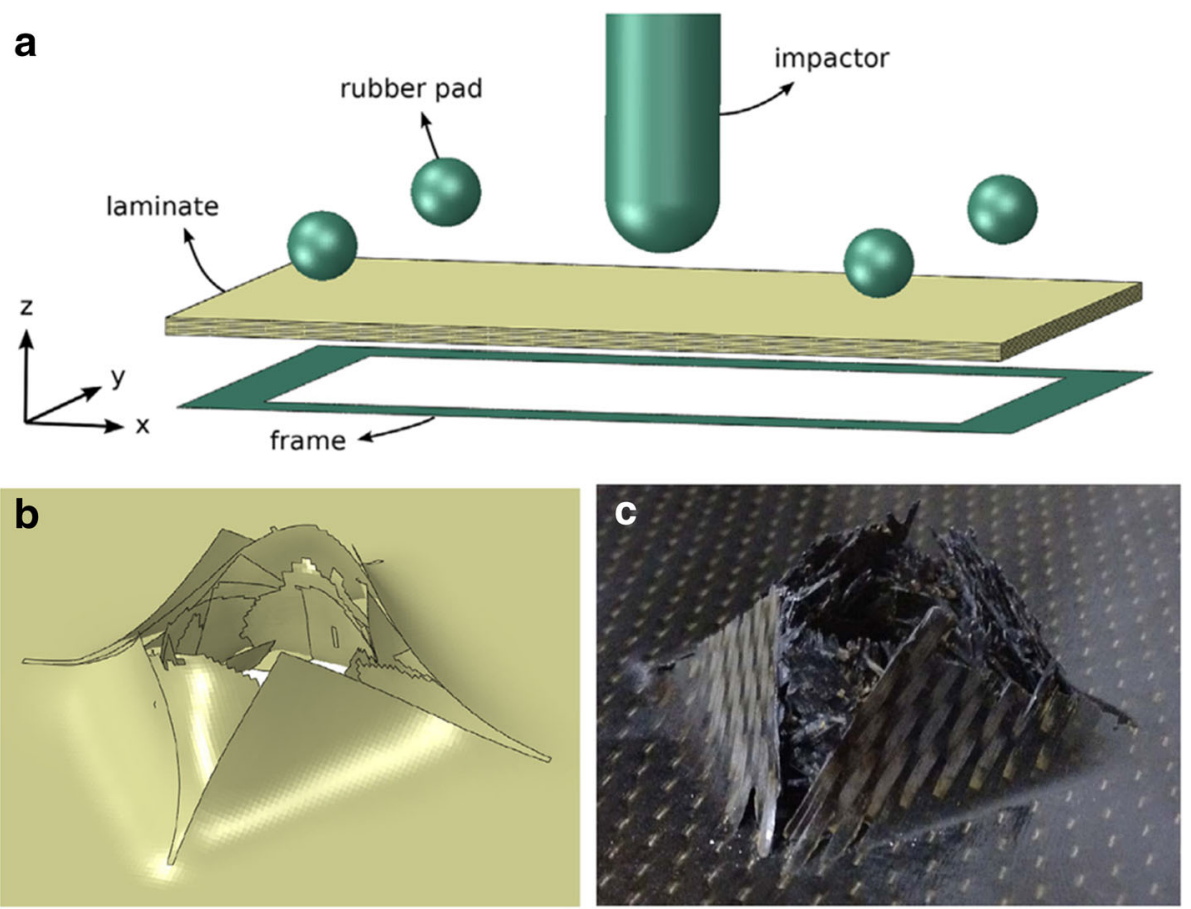

Fig. 15 a Schematic of modelled drop tower test setup; predicted $\mathbf{b}$ and experimentally observed $\mathbf{c}$ failure patterns at back face of woven plate after $400 \mathrm{~J}$ impact (Schwab et al. 2016)

to the weaving and braiding patterns. Pascal et al. (2015) described an extension of a semi-continuous approach in order to take into account the weaving pattern geometry. In this model, ply bundles were represented by $1 \mathrm{D}$ rod elements connected by nodes to 4 edges of a quadrilateral shell element. Properties of the rods were adapted to represent local strain concentration. For delamination modelling, each ply was connected with a shell-to-shell interface element with a cohesive law. The main assumption about the damage mechanism was as follows: when resin was damaged, the local structure was lost and the ply's bending stiffness was affected. The bundles were temporally and locally relaxed until, carrying all the loads, they failed in tension. Matrix failure was modelled with DVs for each local fabric direction $d_{i}(i=$ 1 and 2). $d_{1}$ affects $E_{1}$ and $G_{13}$ while $d_{2}$ affects $E_{2}$ and $G_{23}$. These variables were functions of the energy-release rates $Y_{i}(i=1$ and 2$)$, calculated from bending strains and the Poisson's ratio of the resin material. Damage evolution was given by

$$
d_{i}=\left\{\begin{array}{cl}
\frac{\left\langle\sqrt{Y_{i}}-\sqrt{Y_{0}}\right\rangle_{+}}{\sqrt{Y_{c}}} & \text { if } d_{i}<1 \\
1 & \text { otherwise }
\end{array}(i=1,2),\right.
$$

where $Y_{0}$ controls the damage initiation, $Y_{c}$ the damage evolution. $\sqrt{Y_{i}}-\sqrt{Y_{0_{+}}}$donates positive part of the difference between $\sqrt{Y_{i}}$ and $\sqrt{Y_{0}}$. Besides, a third independent DV $d_{12}$ was implemented to model the final in-plane shear rupture. The bundle rupture in tension was assumed to be brittle. Therefore, the classic maximum-tensile strain criterion was used for rupture of the rods. In order to avoid numerical instabilities, when the maximum strain criterion was reached, the rod's normal force $F_{11}$ was smoothly decreased by the use of a characteristic time $\tau$ as follows:

$$
F_{11}=F_{11}^{*}\left(1-\exp \left(\frac{t^{*}-t}{\tau}\right)\right)
$$

where $t^{\prime \prime}$ is the exact time at which the criterion is reached and $F_{11}^{*}$ the force stored at time $t^{*}$. Comparisons with experimental data from drop-weight and gas-gun tests showed good accuracy of the force history and damage size and shape. As shown in Fig. 16, the modelling strategy was able to capture complex macro-crack paths observed experimentally as well as micro-cracking and delamination in the resin. With the numerical simulations, the influence of microstructure parameters on the impact behaviours could be revealed and the microstructure could be optimized.

In modelling of LVIs, recent studies paid much attention to capture BVID, i.e. delamination and matrix cracking. A drawback of the continuum-element discretisation within these models was rather large computing times, even for models at a coupon level. Therefore, 


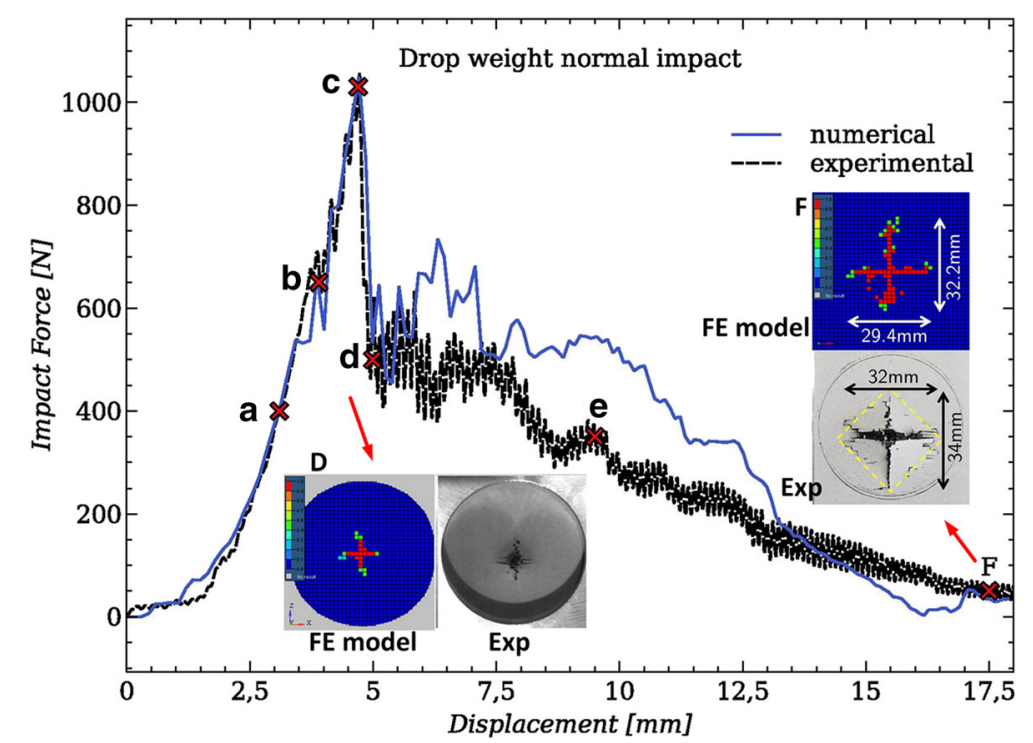

Fig. 16 Load-displacement curves of drop-weight impact test and bottom-face damage patterns (experimental and numerical results) at specific points (Pascal et al. 2015)

although the advanced strategy was able to represent local strain and stress fields related to the interlacing braided and woven architectures, it could hardly be used for large-scale structures.

\section{High-velocity and ballistic impact}

Different from a drop-weight scenario, the kinetic energy of a projectile under ballistic impact is observed to dissipate in the form of distinctive mechanisms. The predominant energy absorption mechanisms of laminates under high-velocity impact are related to kinetic energy of moving a cone formed on a distal side of the target, frictional losses during penetration and energy absorption related to failure modes, such as shear plugging, tensile fibre failure of primary yarns, fibre debonding, fibre pull-out, matrix cracking (intra-laminar) and interlaminar delamination. For braided composites, although advanced numerical models were employed to predict their mechanical properties and failure modes, some of them are not suitable to study their ballistic behaviour because of high strain rates and high pressure conditions in the impact area in high velocity-impacts. It is well known that carbon/epoxy composites exhibit significant strain-rate sensitivity under such conditions.

Qiao et al. (2008) reviewed topics of impact mechanics and computational modelling of impacts (such as FE method, mesh-free methods and peri-dynamics). In their review, constitutive models of strain rate-dependent polymeric composites and their implementation in micromechanics models were briefly introduced. They also developed a nonlinear finite-element code (e.g., LSDYNA) for impact and failure analysis. At an early stage, the main purpose of modelling the ballistic response of composites was not their damage-evolution mechanisms. Instead, research was mostly aimed at macro ballistic parameters including residual velocities and maximum levels of dynamic displacement (Gower et al. 2008). Specifically, in terms of textile composites, the focus was on different composite features (like a fabric type and its multi-layer structure), projectile geometry, impact velocity and effect of friction of fabric yarns on the response of composites (Zeng et al. 2006; Rao et al. 2009a). Therefore, analysis of failure mechanisms still remains challenging in terms of accuracy of results and efficiency of the methodology.

The most popular approach to modelling the ballistic impact is a macro-homogeneous method, meaning that every composite layer is modelled as a homogeneous orthotropic material without making a distinction between the yarns and the matrix, but considering the whole as a single part. Sevkat et al. (2009b) adopted a nonlinear orthotropic damage model to study damage in composite beams subjected to ballistic impacts with the instantaneous stiffness-degradation scheme (described in Section 2.2). In addition, LS-DYNA with a Chang-Chang linear-orthotropic damage model was used for comparison. A good agreement between experimental and FE results was found from comparisons of dynamic strains and damage patterns. Gu and Ding (2005) refined the so called fibre inclination model to analyse ballistic penetration properties of 3D braided composite. The inclined UD lamina was established, containing a braided yarn with the same diameter and fibre volume fraction as in the $3 \mathrm{D}$ braided composite at the actual microstructure. 
The obtained results indicated that the refined quasimicrostructure model could approximately simulate the real ballistic-impact damage of 3D-braided composites. Cui et al. (2011) further modified the fibre inclination model with a FE code in LS-DYNA to simulate ballistic penetration of a hemispherical cylindrical steel projectile into a 3D angle-interlock woven composite. In both approaches, the instantaneous stiffness-degradation scheme was used while the strain-rate effect was underestimated.

Applying the continuum damage mechanics, Goldberg and co-workers developed a sub-cell model for tri-axial braided composite (Littell et al. 2009a; Li et al. 2009; Goldberg et al. 2012). In this method, a unit cell of the braided composite was modelled as a series of shell elements, with each element modelled as a laminated composite. By defining integration points of these shell elements, a sequence and angles of layer could be assigned easily, and ballistic simulations could be performed with high efficiency with LS-DYNA. Although all the research works mentioned above employed shell elements to model braided composites, those modelling schemes could not reproduce properly the deflection and global deformation of a composite plate due to a transverse impact, especially for thick plate sections. The interaction between layers and delamination failure modes could not be simulated as well. In simulations of impact tests on flat panels, although the calculated penetration velocity correlated reasonably well with experimentally obtained values, the predicted damage patterns did not reflect experimental observations. This difference was possibly attributed to the use of quasi-static mechanical properties of the modelled composites. Since anisotropic stiffening is probably attributable to strainrate effect, further investigation should be carried out.

Liu et al. (2013) used a FE method based on the CDM model to predict failure responses of tri-axial braided carbon fibre/epoxy composite plates under impacts of projectiles with different shapes. This material model was based on the Hashin failure criteria with five failure modes: tensile and compressive fibre failure, fibre crushing, through-thickness matrix failure and delamination. This constitutive description could simulate progressive damage in composite laminates by controlling strain softening after failure in high-velocity impacts. The $\mathrm{CDM}$ formulation took into consideration post-failure mechanisms in a composite plate characterized by an exponential reduction in material stiffness, as mentioned in Section 2.2.2. The effect of the strain rate on ply strength was then modelled with strain-rate-dependent functions expressed as

$$
\left\{S_{r t}\right\}=\left\{S_{0}\right\}\left(1+C_{1} \ln \frac{\dot{\bar{\varepsilon}}}{\dot{\varepsilon_{0}}}\right)
$$

where $C_{1}$ is the strain-rate constant for strength properties (chosen as 0.1), $\left\{S_{0}\right\}$ are the quasi-static reference strength values, $\left\{S_{r t}\right\}$ are the rate-dependent strength values, $\dot{\overline{\varepsilon_{0}}}$ is the quasi-static reference strain rate and $\dot{\varepsilon}$ is the associated strain rate. The evolution of a penetration resistance force, energy absorption and damage with time during the impact process was predicted. The results showed that tension failure in a back surface, compression/shear failure along a projectile's perimeter and delamination failure were dominant mechanisms in the penetration phase. Deformation of the composite plate and tension of carbon fibres were effective energy-absorption modes. The authors also addressed differences between the impact processes and damage mechanisms related to blade-like and cylindrical projectiles, as shown in Fig. 17.

The above models were generally created using a macro-homogeneous approach in order to obtain reliable results with a reduced computational cost and effort. However, detailed damage patterns observed in experiments were missing. For instance, cracks and damage propagate along fibre-yarn directions when braided composites are subject to impact. Therefore, it is better to include the braid architecture directly into a FE model. A technique to include yarns was adopted by Barauskas and Abraitienè (2007) and Rao et al. (2009b). A difference between reproducing yarns around the impact area with a square shape and primary yarns in their entire length was evaluated. In addition, these works focused on guaranteeing the continuity of physical properties between different areas. Hence, the continuity between a meso-mechanical region and an orthotropic shell zone was analysed from stress-wave propagation. The yarns were reproduced individually, using shell elements instead of 3D elements.

Recently, some studies (Pan et al. 2014; Wan et al. 2015) suggested FE models to explore failure mechanisms of 3D braided basalt/epoxy composite materials under compressive impact with high strain rates. The meso-structure model was based on real architecture of the 3D braided composite. The whole structurebuilding process was implemented in the commercial CAD software CATIA V5-R20. Ductile and shear criteria with an isotropic plastic-damage model considering the strain-rate effect were selected in the FE models to simulate the failure and damage processes at the meso-scale levels. The ductile criterion was specified by providing the equivalent plastic strain at the onset of damage, $\bar{\varepsilon}_{D}$, which was a function of stress triaxiality $\eta$ and strain rate $\dot{\varepsilon_{D}}$ :

$$
\bar{\varepsilon}_{D}=f\left(\eta, \dot{\varepsilon}_{D}\right)=\frac{\varepsilon_{T} \sinh \left[k_{0}\left(\eta_{C}-\eta\right)\right]+\varepsilon_{C} \sinh \left[k_{0}\left(\eta-\eta_{T}\right)\right]}{\sinh \left[k_{0}\left(\eta_{C}-\eta_{T}\right)\right]}
$$




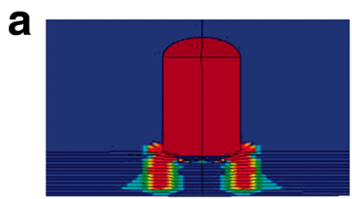

$6 \mathrm{~ms}$

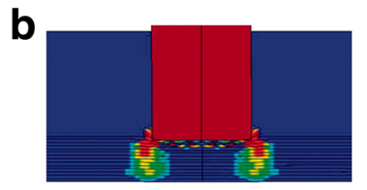

$6 \mathrm{~ms}$

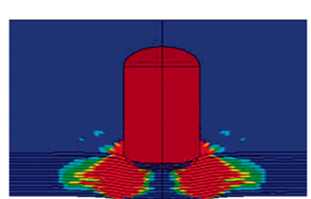

$16 \mathrm{~ms}$

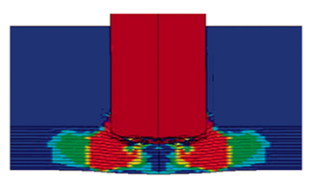

$16 \mathrm{~ms}$

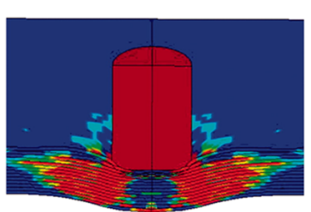

$34 \mathrm{~ms}$

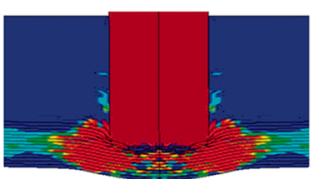

$40 \mathrm{~ms}$

Fig. 17 Delamination evolution mechanism under ballistic impact with cylindrical (a) and blade-like (b) projectiles. In the composite plate, the blue colour represents intact material and the red colour-delamination damage (Lulu et al. 2013)

where $\varepsilon_{T}$ and $\varepsilon_{C}$ are the equivalent plastic strain at ductile-damage initiation for uniaxial tensile and uniaxial compressive deformations, respectively, and $k_{0}$ is a material constant. $\eta=-p / q$ is the stress tri-axiality, where $p$ is the pressure, $q$ is the von Mises equivalent stress. $\eta_{C}=1 / 3$ and $\eta_{T}=-1 / 3$ represent the stress triaxiality in uniaxial tensile and compressive deformation state, respectively. Similarly, the shear criterion assumed the equivalent plastic strain at the onset of damage, $\bar{\varepsilon}_{S}$, as a function of the shear ratio $\theta_{S}$ and the strain rate $\dot{\bar{\varepsilon}}_{S}$. A damage-evolution law was based on energy dissipated during the damage process. The variable $D$ was evaluated up to a limit of 0.2 , at which point the elements were removed; the results showed a good agreement with experimental data. The meso-scale model effectively predicted mechanical properties and failure morphologies of the 3D braided composites with detailed information on distributions of deformation and stress in braiding yarns. Further, the FE results revealed that the braiding structure had a significant influence on thermomechanical failure. A multi-scale approach and the CDA theory were also employed in the study of high-strain-rate compression (Wan et al. 2016).

Both marco- and meso-scale models were built and compared by Bresciani et al. (2016) in order to predict ballistic behaviour of Kevlar 29 plain-woven fabrics with an epoxy matrix. In the macro-homogeneous model, the equivalent mechanical properties were employed while in the meso-scale model, fabrics were simulated with their specific architectures and individual mechanical properties. These two numerical approaches provided a deep insight into a stress state of a target during ballistic impact showing different behaviours of the layers. The results clearly demonstrated that the first layers (during impact) were subjected to high shear stresses and that the yarns in the rear layers underwent severe in-plane tension stresses. Therefore, a multilayer composite plate with different materials and structures across its thickness can be a potential solution to improve its resistance. In general, the meso-scale model provided more accurate results, as shown in Fig. 18, both for quantitative (residual velocities and transverse wave propagation) and qualitative analysis (delamination and local damage). The drawbacks of this modelling technique are its high computational cost; for instance, in the Bresciani's study, the computational time was on average of 6 to 7 times higher than that for the macro-heterogeneous model.

Besides drop-weight and ballistic impacts, extensive modelling studies were carried out to deal with impact problems in other situations, such as Izod-type impact (Ullah and Silberschmidt 2015), tube crush (McGregor et al. 2007; Zhou et al. 2015), air blast, under-water blast (Zhang et al. 2016b, 2017b), etc. In most of these impact scenarios, a strain-rate dependency and a homogeneous method were considered due to high impact energy so that geometrical features and damage modes of textile composites were ignored. Therefore, such investigations applying relatively arbitrary damage-evaluation schemes are beyond the scope of this review.

In summary, explicit simulations were developed to study a response of braided composites to impacts using ABAQUS/Explicit and LS-DYNA. Generally, the failure criteria and damage-evolution models used in these cases were similar to those in studies of static loading. According to this progress, the overall response of braided composites under impact was better captured with FE method than before, including such features as BVID, impact force, duration time, maximum displacement and residual properties of targets. However, improvements are still needed to overcome various limitations. For instance, the accuracy of predictions is based on material parameters, which are obtained mostly from complicated experimental studies or from the literatures. Furthermore, these 


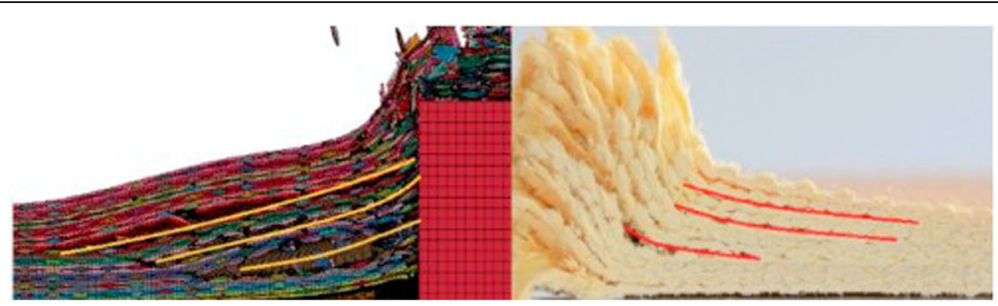

Fig. 18 Comparison of experimental tests with damage morphology obtained with meso-heterogeneous model (Bresciani et al. 2016)

schemes are still very expensive in terms of computational time, since explicit analyses are necessary to provide detailed information about impacted regions. Finally, it is not possible to generalize results from these studies, since each research is based on impact tests on specific type of textile composites.

\section{Modelling fatigue behaviour of braided composites}

Fatigue deformation, damage and failure are important subjects to investigate long-time service of braided composite materials. For decades, FE methods have been used extensively in fatigue prediction for composite materials. Reviews of an early fatigue-damage modelling work were published by Degrieck and Van Paepegem (2001) and Post et al. (2008). Most of these methodologies were established on the basis of experimental studies of laminates with specific lay-up sequences under specific testing conditions, resulting in distinctive fatigue behaviours and properties. Therefore, some of those methods were difficult to extend to textile composites because of their different structures and failure modes. For braided and woven composites, comprehensive literature reviews (Xu, 2011; Sevenois and Van Paepegem, 2015; Wang et al. 2015) unveiled that considering appropriate damage mechanisms was the key issue for analysis of textile composites subjected to fatigue. The entire fatigue process can be divided into different stages, and each stage involves distinct damage modes. It was also known that different 3D structures induced different fatigue behaviours. According to $\mathrm{Xu}$ (2011), the existing fatigue models can be classified into three categories: Miner's-rule-like models, phenomenological models and progressive-damage models. This section mainly introduces state-of-the-art modelling approaches for fatigue behaviour of braided composites presented in the past few years.

\section{Tension-tension fatigue modelling}

In fatigue studies of textiles composites, the purpose of the experiments is mostly to acquire residual modulus curves and S-N plots from fatigue tests for longitudinal tension-tension, transverse tension-tension, in-plane shear and out-of-plane shear. S-N curves of UD composites are generally used as input for modelling work. Therefore, reliable numerical methods should be developed to link the internal architecture of composites to their apparent properties.

Hao et al. (2015) investigated fatigue behaviour of 3D 4-directional braided composites based on the unit-cell approach using ABAQUS, looking into the effects of fatigue loading direction, braided angle and fibre volume fraction on the fatigue damage evolution and fatigue life. In their approach, the degradation of strength during cycling loading was assumed to follow simple linear degradation with cycles obtained from the $\mathrm{S}-\mathrm{N}$ curve or a constant life diagram. A fatigue modulus was defined as the slope of a line, connecting the minimum stressstrain point with the maximum one in the cycle. S-shaped damage-evolution behaviour with a number of cycles was represented by the following equation (Mao and Mahadevan 2002):

$$
D=q\left(\frac{n}{N}\right)^{m_{1}}+(1-q)\left(\frac{n}{N}\right)^{m_{2}}
$$

where $N$ is the fatigue life at the given load level, $n$ is the number of cycles and other variables are the material parameters; Fig. 19a shows a schematic of accumulation of damage in fatigue. Then, a damage-evolution equation was used to predict degradation of the modulus during fatigue as follows:

$$
E_{d}=E_{0}-\Delta E \times D
$$

where $E_{d}$ and $E_{0}$ are the degraded and original moduli and $\Delta E$ is the drop in modulus between the first cycle and the cycle just prior to failure; the magnitude of $\Delta E$ depends on the maximum fatigue stress. Fig. 19b demonstrates the elastic modulus of the unit cell varied with the fatigue cycles at stress ratio of $90 \%$ under uniaxial and biaxial tensile-tensile fatigue load. The fatigue loads with stress level of $90 \%, 80 \%, 70 \%, 60 \%$ and $50 \%$ were applied to the unit cells, respectively. The results showed that the fatigue behaviour along the braided direction was superior than that perpendicular to it. The fatigue life along this direction decreased with the increasing braided angle, which was inversed for the perpendicular direction. The fatigue life along both the braided direction and perpendicular to it increased with the increasing fibre volume fraction. 

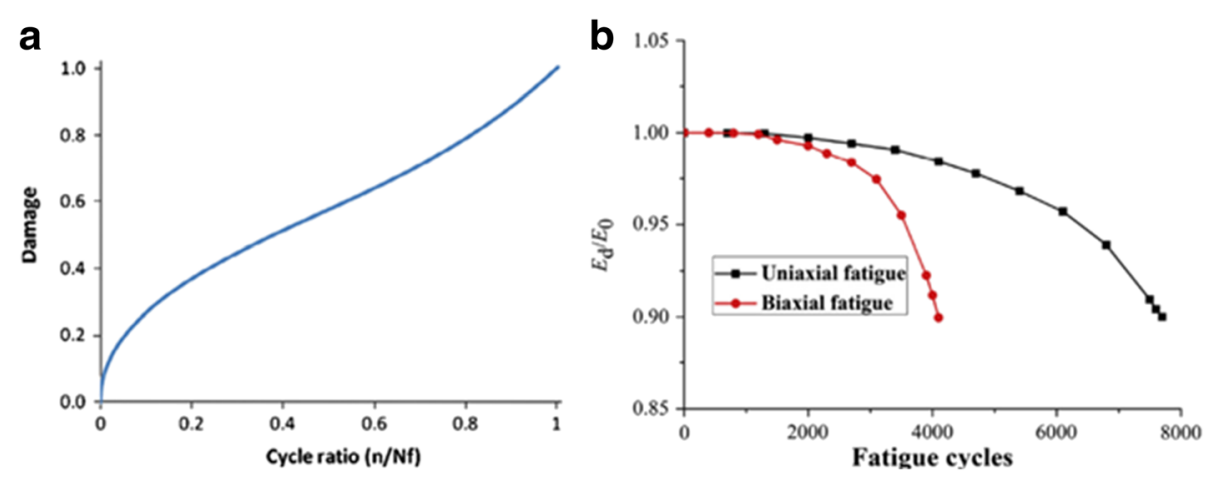

Fig. 19 Schematic diagrams of fatigue accumulation damage (a) and stiffness degeneration under different fatigue loading (b) (Hao et al. 2015)

This life-prediction model did not attempt to account for the actual damage mechanisms; instead, the laminate ply or layup was considered as a quasi-homogeneous structure. So, they assumed that the mechanisms could be captured with the use of fitting parameters or damage indices. Such phenomenological models do not inform their users about the dominant damage mechanism in failure of the structure, preventing the materials engineers to improve the design. To overcome these limitations, the progressive-damage models can be considered since they are able to account for the evolution of damage mechanisms at the micro- or meso-scale. Therefore, the PFA can be used to describe the deterioration of macroscopically observed material properties.

Montesano et al. (2013) improved the fatigue damage model employing quantified parameters of observed damage mechanisms, to investigate fatigue behaviour of a triaxial braided composite at room and elevated temperature. This predictive model captured unique characteristics of fatigue damage evolution in the braided composite with the observed stiffness loss related directly to a crack density. Therefore, exponential fitting of the measured crack densities for both braider yarns $\left(\rho_{b y}\right)$ and yarn interface $\left(\rho_{\text {int }}\right)$ was applied, and cumulative degradation factors $D$ were used to link the crack densities with the macroscopic stiffness degradation. Montesano et al. (2015) further developed this model, linking the fitting parameters with the applied loading to make the model fully mechanism-based. When the material was assumed to be under a state of plane stress, three internal variables representing damage were incorporated to degrade inplane elastic constants. For cyclic loading, DVs $D_{i j}$ were defined related to crack densities for braider yarns $\left(\rho_{b y}\right)$ and yarn interface $\left(\rho_{\text {int }}\right)$

$$
D_{i j}=\alpha_{i j}\left(\alpha_{1} \rho_{b y}^{\beta_{1}}+\alpha_{2} \rho_{i n t}^{\beta_{2}}\right)
$$

where $\alpha_{1}, \alpha_{2}, \beta_{1}$, and $\beta_{2}$ are the empirical material constants and $\alpha_{i j}$ are the scalar parameters corresponding to particular material directions. The $\alpha_{i j}$ terms ensure that the effects of damage correspond to the material symmetry, and, thus, the material maintained its orthotropic symmetry during damage evolution. From the thermodynamic potential of the damaged material, the resulting damaged stiffness tensor $\boldsymbol{C}(\boldsymbol{D})$ is defined as

$$
\boldsymbol{C}(\boldsymbol{D})=\left[\begin{array}{ccc}
\frac{\left(1-D_{11}\right) E_{11}}{1-v_{12} v_{21}} & \frac{v_{12}\left(1-D_{22}\right) E_{22}}{1-v_{12} v_{21}} & 0 \\
& \frac{\left(1-D_{22}\right) E_{22}}{1-v_{12} v_{21}} & 0 \\
\text { sym } & & \left(1-D_{12}\right) G_{12}
\end{array}\right]
$$

where $v_{12}$ and $v_{21}$ are the major and minor Poisson ratios, respectively. It was assumed in this study that the damage terms $D_{11}$ and $D_{22}$ were only effective when the corresponding strains were positive, i.e., $E_{11}$ and $E_{22}$ were not affected by compressive loading states. For numerical computations, a UMAT subroutine was called at every material integration point of meshed-elements in every solution load step. During the convergence iterations, the subroutine can be called multiple times in each load step. The numerical results were validated by experimental data of composite components using DIC, showing the capability of the developed model to predict damage evolution and material-property degradation in a tri-axial braided carbon-fibre/polymer-matrix component. However, critical damage modes such as delamination and fibre fracture must be considered in the progressive damage process if fatigue failure is to be predicted. In addition, the effects of compressive stresses on damage evolution should be considered in the model, as well as defining a suitable failure criterion to predict fatigue failure.

These points were improved by Xu et al. $(2015 \mathrm{a}, \mathrm{b})$ who presented a numerical procedure for prediction of initiation and evolution of fatigue damage on the level of a unit cell of textile composites under tension-tension loading. The proposed scheme comprised three computational modules, A, B and C, shown in Fig. 20. In 


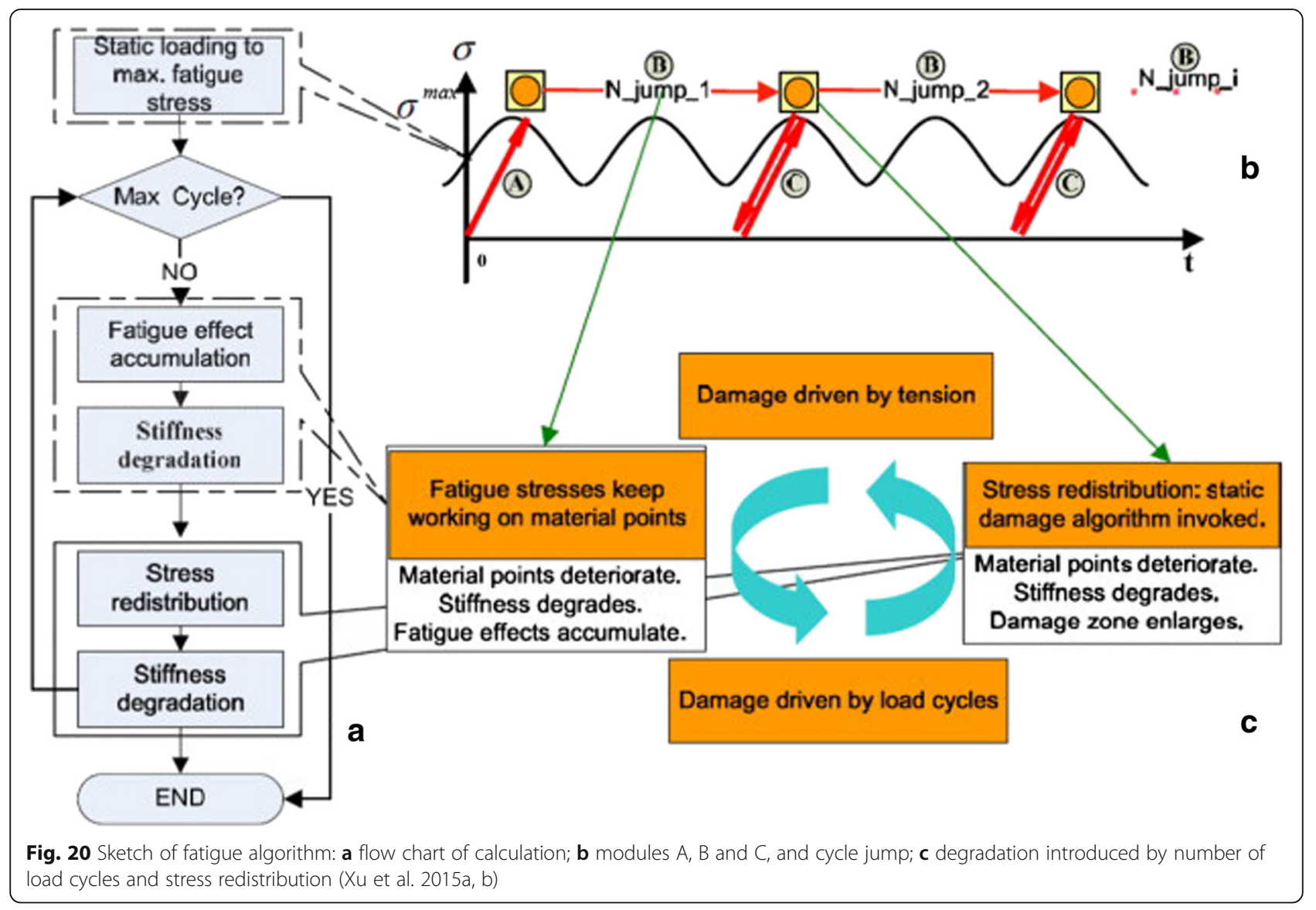

module A, quasi-static loading is applied to an intact unit cell as the first half cycle. Then, in module B, the material is 'worn out' due to the increasing number of load cycles. Finally, in module $\mathrm{C}$, the static module A is invoked again, simulating one load cycle after $\mathrm{N}$ cycles. A single layer of a twill-weave carbon/epoxy resin composite was modelled as a unit cell in the FE analysis. This modelling work was additionally developed based on the CDM approach with a UMAT subroutine. But failure criteria for the yarns and the matrix were established in the fibre direction and in the transverse direction. The applied failure criterion was based on the notions of 'crack plane' and 'critical plane' by Liu and Mahadevan (2007) in planar stress states:

$$
\sqrt{\left(\frac{\sigma_{c}}{f(N)}\right)^{2}+\left(\frac{\tau_{c}}{t(N)}\right)^{2}+k\left(\frac{\sigma_{c}^{H}}{f(N)}\right)^{2}}=\beta .
$$

This model is a second-order combination of the peak values (magnitudes) of cyclic normal stress $\sigma_{c}$, shear stress $\tau_{c}$ and hydrostatic stress $\sigma_{c}^{H}$ (mean normal stress) acting in the critical plane (subscript 'c' refers to 'critical plane'). $f(N)$ and $t(N)$ are tension-tension and shear fatigue strengths for the load cycles $N$, represented by the input S-N curves for a comparable UD composite. $k$ and $\beta$ are the material parameters, which can be determined in uniaxial and torsional fatigue tests. The Palmgren-Miner's rule was applied to both the fibre direction $f(N)$ and the transverse direction $t(N)$ to predict the fatigue failure of the material under the loading blocks. Subsequently, the type of failure was determined, and stiffness of the failed element reduced according to the rules used by Zako et al. (2003), presented in Eq. (13). Using this numerical algorithm, two types of twill-weave carbon fibre/epoxy composite materials with different geometry of reinforcement (in terms of the tow size and crimp) were investigated under tension-tension fatigue loadings $(85 \%, 80 \%$ and $75 \%$ of static strength) (Xu et al. 2016). The results showed that the model was able to predict the respective materials' fatigue lives and locations of fibre ruptures that are introduced by stress concentration. Higher crimp in the woven composite resulted in higher stress concentration and shorter fatigue lives. Although delamination was not taken into account, the model still has many advantages. However, according to Rolfes et al. (2011), such a model based on continuum mechanics may suffer from the meshdependency problem. Further studies are expected in the future to improve accuracy of predicting the modulus loss. 


\section{Bending fatigue modelling}

In contrast with tension-tension fatigue loading, analysis of three-point-bending fatigue properties of 3D braided composites is mainly limited to experimental studies; few works developed FE modelling methods. Sun et al. (2012a, b) suggested a unit-cell model of a 3D braided composite based on its microstructure. A UMAT subroutine was written and incorporated in the commercial FE code ABAQUS/Standard to assess the stiffness degradation and maximum deflection of the braided composite during each loading cycle. In this study, stiffness degradation was evaluated based on a nondestructive testing technique used to inspect bending fatigue damage. A power-function model was firstly proposed by Ye (1989), which could predict the value of normalized stiffness at the $n^{\text {th }}$ cycle. The model was expressed as:

$$
D=\frac{E_{n}}{E_{0}}=1-[n C(m+1)]^{1 /(m+1)} \sigma_{\max }^{2 m /(2 m+1)},
$$

where $D$ is the stiffness index of the 3-D braided composite, $E_{n}$ is the elastic modulus at the $n^{\text {th }}$ cycle and $E_{0}$ is the initial modulus. $C$ and $m$ are the material constants determined by least-square fitting, $\sigma_{\max }$ is the stress level. Correspondingly, a stiffness-degradation curve, a maximum deflection curve and fracture patterns were obtained from the FE simulations.

Based on this approach, Wu and Gu (2014), Wu et al. (2014b)) published several studies on fatigue deformation and damage of a 3-D 4-step rectangular-braided composite under three-point low-cyclic bending loading. The purpose was to analyse the effect of the braided preform structure on fatigue damage mechanisms based on a stress distribution and deformation of fibre tows and resin. In these studies, the yarn structure and matrix were modelled as separate entities in a FE model of the entire bended specimen. For damage initiation and evolution, two approaches were proposed based on CDM.

For the first approach, the fatigue damage criteria were divided into two classes because failure of the 3D braided composite had two main modes under threepoint bending cyclic loading. The one was the material degradation and expansion. Another was interface debonding and its propagation. The criteria for damage initiation and extension in materials under fatigue were characterized by the accumulated hysteresis energy $\Delta \mathrm{W}$ per cycle. Specifically, the damage propagation stage started after the damage-initiation criterion was satisfied

$$
N_{0}=k_{1} \Delta W^{m_{1}}
$$

and

$$
d D / d N=k_{2} \Delta W^{m_{2}} / L,
$$

where $N_{0}$ is the number of cycles for damage to initiate, $d D / d N$ is the rate of damage with cycles. Here, $D$ is degradation of material's stiffness $(0-1), L$ is the characteristic length of the element and the rest are the material constants. The processes of initiation and growth of interface debonding under fatigue loading were both expressed using the Paris law, related to the relative fracture energy release rate and the interface debonding growth rate (Paris et al. 1961). Using this approach, the stress distribution, stress hysteresis and failures of fibre tows and resin at different parts of the 3-D braided composite material were obtained with the FE calculations. The damage process assessed in FE modelling also revealed three steps of damage accumulation in the 3D braided composite under bending fatigue: (i) sharp stress decline; (ii) smooth stress decline and (iii) complete damage.

In the second modelling method (Wu et al. 2014b), a modified Hashin fatigue failure criterion, combining cyclic stress with a static failure criteria, was applied to justify different failure modes (Shokrieh and Lessard 2000). Then, an improved expression for the damage growth and accumulation under fatigue loading was adopted (Van Paepegem and Degrieck 2001):

$$
\frac{d D}{d n}= \begin{cases}\frac{A\left(\frac{\Delta \sigma}{\sigma_{T S}}\right)^{c}}{(1-D)^{b}} & \text { in tension } \\ 0 & \text { in compression }\end{cases}
$$

where $D$ is the local DV, $n$ is the number of cycles, $\Delta \sigma$ is the amplitude of applied cyclic load, $\sigma_{T S}$ is the tensile strength, and the rest are the material constants. Interface debonding was not considered in this approach. With this approach, the distributions of stresses and strains, a change of bending displacement, stiffness degradation and load-displacement curves were calculated for three different stress levels. Stress concentration and large deflection were found to occur at the middle of the composite panel and both ends of the bottom area. At higher stresses, the entire composite was subjected to larger deformation and faster damage accumulation, resulting in a swift fatigue failure. The model was shown to describe failure locations in the yarns and matrix (Fig. 21). Therefore, the authors claimed the possibility of extending the RUC model to design of bending fatigue performance for other 3D braided composite structures. However, it is difficult to evaluate these methods properly without more reasonable comparisons with experimental results.

\section{Repeated impacts modelling}

Unlike the case of a single low-velocity impact discussed in Section 3.1, in composite that already experienced 

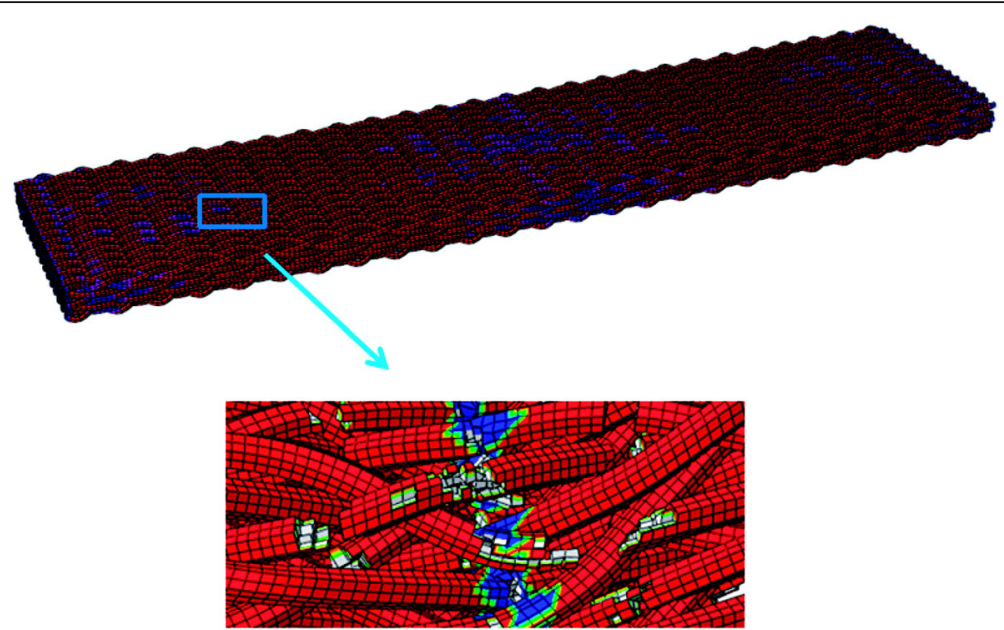

Fig. 21 Yarn and matrix interface debonding of composite in 10th cycle (Wu et al. 2014b)

some impact damage, dynamics of subsequent impacts at the same location can be affected. Studies of repeated impacts on composite structures aim at understanding of the growth of damage as a function of the number of impacts. When large numbers of impacts (with regard to the service life) are considered, the term "impact fatigue" also applies. Multiple impacts of composite materials refer to cases when several impacts occur simultaneously or quasi-simultaneously (Silberschmidt 2016). However, previous studies of behaviour of composite after repeated impacts mainly focused on laminated composites and experiments only. A few studies employed numerical simulations to establish analytical models, with much fewer works on braided composites. In this section, some numerical studies in this area are introduced as illustrations.

One of the pioneer work conducted by Chakraborty (2005) performed a 3D transient-dynamic finite-element analysis of multiple impacts on FRP laminated plates. The code developed had a capability to allow impactors of different masses to strike with different velocities at different locations of the plate surface at different intervals of time. Cromer et al. (2012) studied the effect of multiple noncoincident impacts on compression-after-impact (CAI) properties of glass/epoxy laminates and offered a FE model to predict residual flexural strength based on the apparent modulus and damage dimensions. Using ABAQUS, a simplified damage model was combined with stress-based failure criteria and reduced in-plane moduli to predict CAI. However, only a general idea about the analytical scheme was provided in these models, without details with regard to damage evolution and respective mechanisms.

The first modelling study of multi-impacts with sequences of different energy levels was performed by Amaro et al. (2013). In this study, the influence of repeated low-velocity impact with different energy levels on glass-fibre/epoxy laminates was verified. A 3D numerical approach was developed to understand damage evolution in the studied cases. Cohesive-zone elements were used to simulate delaminations. Considering the classical laminate theory, the laminate layers were homogenised with 8-node iso-parametric solid elements to get global elastic properties. The results showed that damage increased with the level of the highest impact event in each sequence; For instance, a sole impact of $3 \mathrm{~J}$ was more detrimental in terms of cumulative damage than multi-impact events. It should be noted that the effect of shear stress of the neighbouring layers on interface delamination was not accounted in in this method.

To improve this point, Tian et al. (2016) established an adaptive model to analyse the influence of different multiple impacts with the same total impact energy on glass laminate aluminium-reinforced epoxy (GLARE). A drop-hammer low-velocity impact-testing machine was employed to verify the model's reliability, and numerical simulations were based on a user subroutine of the LSDYNA software. During impact, various failure modes were induced in GLARE. Therefore, by modifying the failure criteria of Hou et al. (2000), five mode-dependent failure criteria with an instantaneous stiffness degradation method were adopted, as listed in Table 5.

In a post-processing module, failure and damage elements as well as stress-analysis results were obtained. When multiple impacts on GLARE were analysed, a user subroutine was defined to establish a connection between the second and first impacts; the calculation results for the first impact were considered as initial conditions for the second impact. Hence, analytical damage results showed that a single-impact area of internal damage was larger, when the impact energy was high; therefore, multiple impacts with bigger initial impact energy induced severe internal damage. 
Table 5 Failure criteria and respective degradation adopted by Tian et al. 2016

\begin{tabular}{lll}
\hline Failure & Criteria & Degradation \\
\hline Fibre tension failure $\left(\sigma_{11} \geq 0\right)$ & $\left(\frac{\sigma_{11}}{X_{T}}\right)^{2}+\frac{T_{12}^{2}}{\left(S_{f}\right)^{2}}+\frac{T_{13}^{2}}{\left(S_{f}\right)^{2}} \geq 1$ & $\begin{array}{l}E_{11}, E_{22}, G_{12}, G_{23}, G_{13}, U_{12}, U_{23}, U_{13} \\
\text { degrade to } 0.1 \text { of their original value }\end{array}$ \\
Fibre compression failure $\left(\sigma_{11}<0\right)$ & $\left(\frac{\sigma_{11}}{X_{C}}\right)^{2}+\frac{\tau_{12}^{2}}{\left(S_{f}\right)^{2}}+\frac{T_{13}^{2}}{\left(S_{f}\right)^{2}} \geq 1$ & $\begin{array}{l}E_{11}, E_{22}, G_{12}, G_{23}, G_{13}, U_{12}, U_{23}, U_{13} \\
\text { degrade to } 0.18 \text { of their original value }\end{array}$ \\
Matrix cracking $\left(\sigma_{22} \geq 0\right)$ & $\left(\frac{\sigma_{22}}{Y_{T}}\right)^{2}+\frac{\tau_{12}^{2}}{\left(S_{12}\right)^{2}}+\frac{\tau_{23}^{2}}{\left(S_{23}\right)^{2}} \geq 1$ & $\begin{array}{l}E_{22}, G_{12}, G_{23} \\
\text { degrade to } 0.4 \text { of their original value }\end{array}$ \\
Matrix crushing $\left(\sigma_{22}<0\right)$ & $\frac{1}{4}\left(\frac{-\sigma_{22}}{S_{12}}\right)^{2}+\frac{Y_{C}^{2} \sigma_{22}}{4 S_{12}^{2} Y_{C}}+\frac{\sigma_{22}}{Y_{C}}+\frac{T_{12}^{2}}{\left(S_{12}\right)^{2}} \geq 1$ & $E_{22}, G_{12}, G_{23}$ \\
Interface delamination $\left(\sigma_{33} \geq 0\right)$ & $\left(\frac{n \sigma 23}{S_{123}}\right)^{2}+\left(\frac{n+1 \sigma 23}{S_{123}}\right)^{2}+\left(\frac{\sigma_{33}}{Z_{T}}\right)^{2}+\left(\frac{\sigma_{22}}{Y_{T}}\right)^{2} \geq 1$ & degrade to 0.5 of their original value \\
\hline
\end{tabular}

The studies mentioned above focused only on fibremetal-laminate (FML) composites or laminated composites. To the authors' knowledge, there is no FE model for braided composites to study their responses to repeated impacts so far. To some extent, these methods certainly have reference value.

In this section, various approaches used for modelling fatigue damage evolution in braided composites were reviewed. The ideas behind these methods are actually similar, i.e.: to describe the residual strength or stiffness during fatigue loading in a reasonable way. Typically, such descriptions can be based on S-N data, nominal damage accumulation laws and specific observed damage mechanisms. Therefore, the models are mostly empirical, phenomenological, statistical or mechanistic in nature (Kavousi Sisi et al. 2015). Considering their high computational time, fatigue simulations are mainly carried out with macroscopic models. Sometimes they do not consider evolution of the underlying damage mechanisms and, therefore, cannot be used for damage tolerance analysis. For the employed damage-accumulation laws, mathematical fitting always need some empirical damage parameters, which have no direct physical basis; so, extensive testing is often required for their definition. PFA is still regarded as the most suitable way to analyse the damage tolerance of composite structures, because damage states in composites can be effectively presented by internal state variables and material constitutive equations.

\section{Conclusions}

This paper reviewed main damage-evolution modelling studies of braided composites, from 2011 to the present day, with regarded to static, impact and fatigue loading regimes. For each regime, most broadly used failure criteria and damage-mechanics based schemes for predicting progressive failure in braided composites were presented and analysed. Although most of these approaches were developed initially for UD laminated composites, they were modified and improved to accommodate various characteristics of braided composites. Considering their orthotropic nature, tensor polynomial criteria such as Tsai-Wu type criterion were modified for homogeneous braided composite models. To predict mechanical behaviour of braided composites accurately, a meso-scale RUCs with yarn interlacing was applied. In such models, mode-dependent failure criteria based on the Hashin-type schemes were developed. Thus, several different failure modes of braided composites under mechanical loadings were included, such as fibre fracture, fibre kinking, matrix cracking, matrix crushing, nonlinear shearing and delamination. Correspondingly, for each failure mode, relevant damage-evolution relations were developed. The instantaneous stiffnessdegradation method was a simple and efficient approach to implement in FE environment. However, magnitudes of stiffness reduction factors cannot be given in a universal way. More advanced evolution laws based on continuum damage mechanics were validated and proved effective for braided composites. The damage states associated with different failure modes were described with internal DVs. In these studies, the evolution of DVs could be presented in a linear, an exponential or other forms. These PFA approaches were not only suitable for static FE analysis, but also effective in dealing with dynamic problems, including low-velocity impact and even ballistic perforation. More complicated mechanics was needed when analysing responses of braided composites to cycling loading. Although many attempts were successfully implemented for UD composites, studies focused on this aspect in braided structures were quite a few.

In order to enhance accuracy of damage modelling for braided composites, extensive efforts were made in recent few years. Since behaviour of braided composites is affected significantly by their micro- and meso-scale geometries, most numerical damage models were based on micro-mechanical responses of constitutive materials. Such a multi-scale approach was proved effective, with information for different length scales delivered from the local to the global one. The MMF and MCT theories were further developed to improve accuracy for multiscale models. In terms of advanced damage mechanics, more failure modes observed in experiments were included in prediction models, for instance, failure in 
out-of-plane directions, yarns/matrix interface, nonlinear shear failure modes, etc. Continuum damage mechanics based on fracture energy showed a better capability to evaluate internal damage states of braided composites. In high-velocity impact and fatigue modelling, strain-rate dependent problems were also raised and discussed. Finally, the recent progress in FE modelling techniques could improve computational performance. In this area, advanced meshing techniques were suggested and comparison studies with different boundary conditions were conducted. Although many modelling attempts reported results consistent with experimental data, they are not universally applicable to all the braided structures. So, further studies are also needed to analyse the effect of braiding parameters, with more types of fabric architectures and complicated loading conditions in the future.

However, one of the problems associated with these attempts is reduction of the computational efficiency. Generally, micro- and meso-scale models of braided composites pose certain constraints for industrial designers with regard to strict efficiency and cost limitations. Therefore, it is quite crucial to balance the accuracy and efficiency of damage-evolution modelling for complex structures such as braided composites. In the reviewed studies, simple failure criteria and arbitrary degradation models were applied to reduce the computational time. The choice of failure analysis methods was flexible. For example, debonding at the yarn/matrix interface was usually not considered in micro- and meso-scale models under tensile loading to avoid convergence problems. Instead, delamination was one of important failure modes in bending or low-velocity impact modelling. Moreover, 3D solid elements were widely used in meso-scale analysis because of orthotropic stress states, and shell elements were applied when homogeneous models were developed for whole composite structures. Therefore, more future work should be carried out to increase the accuracy while not increasing the computational cost.

Inspired by the previous efforts, four crucial problems are highly recommended to address when modelling damage of braided composites in the future: (a) Interface problem. Generally, the cohesive elements are inserted at pre-assigned positions when dealing with onset of matrix cracking. However, matrix cracks may occur at many other locations in a braided structure. Ideally, cohesive elements should be placed at more locations instead of limited number of pre-defined positions. To solve interface problem, load redistribution within the unit cell should be captured, and a statistic distribution of material properties for cohesive elements and solid elements are also suggested to be considered in the model. (b) Complicated failure modes and their interactions. One of examples is micro-buckling of fibres in yarns under compressive loading, which plays a significant role in the global behaviour of braided composite structures. Since the yarn cannot be modelled as a solid continuum, a more detailed model of fibres in yarns has to be developed; the instability of fibres in compression has to be incorporated in the material model used for fibre yarn. Besides, the effect of material defects, the effects of fibre reorientation due to large deformation (i.e. scissoring effect) and influence of mode III deformation on braided composites are also worth the attention in future work. (c) Length-scale effect. When converting micro-scale results into meso-scale properties, some of the details are lost in the homogenisation process. For instance, the meso-scale yarn material model only has four strain rate scaling constants (longitudinal stiffness, transverse stiffness, shear stiffness and strength), whereas the micro-scale modelling results have provided a lot more (e.g. strain rate scaling constants for strengths in all loading conditions). Hence, the meso-scale simulations with more detailed material properties would provide interesting results for comparison. It is also a challenge to accurately model a super large composite structure. (d) Influence of service condition and environment. Braided composites are complex in nature, many of their behaviours still remain unclear. In service, the performances of braided composites are also influenced by temperature, moisture and loading directions. Therefore, it is necessary to incorporate these effects on the material parameters, considering a function of thermal-mechanical relationship, in a more complex model. In addition, the aging effect, the edge effect and off-axis effect of braided composites are suggested to be accounted for in a more advanced computational mechanics model. Ultimately, it will be ideal for a knowledge-based automated composite design expert system be established, which would include accumulated understandings and models developed in this area.

\begin{abstract}
Abbreviations
2D: Two-dimensional; 3D: Three-dimensional; BVID: Barely visible impact damage; CAD: Computer-aided design; CAE: Computer-aided engineering; CAl: Compression after impact; CDA: Critical damage area; CDM: Continuum damage mechanics; CZM: Cohesive-zone model; DV: Damage variable; FEM: Finite-element method; FML: Fibre metal laminate; FRPC: Fibrereinforced polymeric composite; GLARE: Glass laminate aluminium reinforced epoxy; GMC: Generalized method of cells; LVI: Low-velocity impact; MCT: Multi-continuum technology; MMF: Micro-mechanics of failure; MMF3: Three-parameter micro-mechanics of failure; NFC: Noncrimp fabric; PDM: Progressive-damage model; PFA: Progressive failure analysis; RUC: Representative unit cell; SFA: Stress-amplification factor; UD: Unidirectional; WWFE-II: Second World-Wide Failure Exercise
\end{abstract}

\section{Acknowledgements}

Financial support to CW in form of Research Scholarship by the Institute for Sports Research, Nanyang Technological University is gratefully acknowledged. $\mathrm{CW}$ is also grateful for the collaboration with the Mechanics of Advanced Materials (MoAM) Research Group at Loughborough University, UK. 


\section{Funding}

The work was supported by Nangyang Technological University through a PhD scholarship award.

\section{Availability of data and materials}

Not applicable.

\section{Authors' contributions}

CW carried out the review work; WS, AR and ZC conceived and supervised the work. All authors contributed to the writing and editing of the manuscript. All authors read and approved the final manuscript.

\section{Ethics approval and consent to participate}

Not applicable.

\section{Consent for publication}

All the data cited from other research groups have consent for publication.

\section{Competing interests}

The authors declare that they have no competing interests.

\section{Publisher's Note}

Springer Nature remains neutral with regard to jurisdictional claims in published maps and institutional affiliations.

\section{Author details}

'School of Materials Science and Engineering, Nanyang Technological University, 50 Nanyang Avenue, Singapore 639798, Singapore. ${ }^{2}$ School of Mechanical, Electrical and Manufacturing Engineering, Loughborough University, Ashby Road, Loughborough LE11 3TU, UK. ${ }^{3}$ Institute for Sports Research, Nanyang Technological University, 50 Nanyang Avenue, Singapore 639798, Singapore

\section{Received: 20 April 2017 Accepted: 10 August 2017}

\section{Published online: 31 August 2017}

\section{References}

Aitharaju VR, Averill RC (1999) Three-dimensional properties of woven-fabric composites. Compos Sci Technol 59:1901-1911

Ahn H, Yu WR (2016) Mechanical analysis of 3D braided and woven composites using fiber-based continuum analysis. Compos Struct 160:1105-1118

Amaro AM, Reis PNB, De Moura MFSF, Neto MA (2013) Influence of multi-impacts on GFRP composites laminates. Compos Part B Eng 52:93-99

Ansar M, Xinwei W, Chouwei Z (2011) Modeling strategies of 3D woven composites: a review. Compos Struct 93:1947-1963

Ayranci C, Carey J (2008) 2D braided composites: a review for stiffness critical applications. Compos Struct 85:43-58

Barauskas R, Abraitienè A (2007) Computational analysis of impact of a bullet against the multilayer fabrics in LS-DYNA. Int J Impact Eng 34:1286-1305

Bazant ZP, Planas J (1997) Fracture and size effect in concrete and other quasibrittle materials. CRC Press. Boca Raton.

Bednarcyk B, Stier B, Simon JW, Reese S, Pineda EJ (2015) Meso- and micro-scale modeling of damage in plain weave composites. Compos Struct 121:258-270

Bilisik K (2012) Multiaxis three-dimensional weaving for composites: a review. Text Res J 82:725-743

Binienda WK (2012) Dynamic testing and characterization of woven/braided polymer composites: a review. Appl Mech Rev 64:50803

Blackketter DM, Walrath DE, Hansen AC (1993) Modeling damage in a plain weave fabric-reinforced composite material. J Compos Technol Res 15:136-142

Bresciani LM, Manes R, lannitti G, Giglio M (2016) Experimental tests and numerical modelling of ballistic impacts against Kevlar 29 plain-woven fabrics with an epoxy matrix: macro-homogeneous and mesoheterogeneous approaches. Compos Part B: Eng 88:114-130

Bogdanovich A (2009) Progressive failure modeling and strength predictions of 3D woven composites. In 50th AIAA/ASME/ASCE/AHS/ASC Structures, Structural Dynamics, and Materials Conference 17th AIAA/ASME/AHS Adaptive Structures Conference 11th AIAA No: 2658

Bogetti TA, Hoppel CP, Harik VM, Newill JF, Burns BP (2004) Predicting the nonlinear response and failure of composite laminates: correlation with experimental results. Compos Sci Technol 64:477-485
Camanho PP, Davila CG, De Moura MF (2003) Numerical simulation of mixedmode progressive delamination in composite materials. J Compos Mater 37: $1415-1438$

Chakraborty D (2005) Response of laminated FRP composites under multiple impact loading. J Reinf Plast Compos 24:1457-1477

Chamis C (1969) Failure criteria for filamentary composites. In Composite Materials: Testing and Design. ASTM International. West Conshohocken.

Christensen RM (2007) A comprehensive theory of yielding and failure for isotropic materials. J Eng Mater Technol 129:173-181

Colombo C, Vergani L (2016) A micromechanical approach to evaluate the postimpact residual stiffness of woven composites. J Compos Mater 50:971-984

Cousigné O, Moncayo D, Coutellier D, Camanho P, Naceur H, Hampel S (2013) Development of a new nonlinear numerical material model for woven composite materials accounting for permanent deformation and damage. Compos Struct 106:601-614

Cox BN, Dadkhah MS, Morris WL (1996) On the tensile failure of 3D woven composites. Compos Part A Appl Sci Manuf 27(6):447-458

Cromer K, Gillespie JW, Keefe M (2012) Effect of multiple non-coincident impacts on residual properties of glass/epoxy laminates. J Reinf Plast Compos 31:815-827

Crookston JJ, Long AC, Jones IA (2005) A summary review of mechanical properties prediction methods for textile reinforced polymers composites. J Mater Des Appl 219:91-109

Cui F, Sun B, Gu B (2011) Fiber inclination model for finite element analysis of three-dimensional angle interlock woven composite under ballistic penetration. J Compos Mater 45:1499-1509

Dai S, Cunningham PR (2016) Multi-scale damage modelling of 3D woven composites under uni-axial tension. Compos Struct 142:298-312

Davies GAO, Olsson R (2004) Impact on composite structures. Aeronaut J 108:541-563

Degrieck J, Van Paepegem W (2001) Fatigue damage modeling of fibrereinforced composite materials: review. Appl Mech Rev 54:279-300

Dixit A, Harlal SM (2013) Modeling techniques for predicting the mechanical properties of woven-fabric textile composites: a review. Mech Compos Mater 49:1-20

Döbrich O, Gereke T, Cherif C (2016) Modeling the mechanical properties of textile-reinforced composites with a near micro-scale approach. Compos Struct 135:1-7

Doitrand A, Fagiano C (2015) Experimental characterization and numerical modeling of damage at the mesoscopic scale of woven composites. 14th Onera-DLR Aerospace Symposium. 119; 1-11

Dong J, Huo N (2016) A two-scale method for predicting the mechanical properties of 3D braided composites with internal defects. Compos Struct 152:1-10

Duvaut G, Lions JL (2012) Inequalities in mechanics and physics. Springer Science Business Media. Berlin/Heidelberg.

Edge EC (2002) A comparison of theory and experiment for the stress-based Grant-Sanders method. Compos Sci Technol 62:1571-1589

Fang GD, Liang J (2011) A review of numerical modeling of three-dimensional braided textile composites. J Compos Mater 45:2415-2436

Fang GD, Liang J, Wang BL (2009) Progressive damage and nonlinear analysis of 3D four-directional braided composites under unidirectional tension. Compos Struct 89:126-133

Garnich MR, Akula VMK (2009) Review of degradation models for progressive failure analysis of fiber reinforced polymer composites. Appl Mech Rev 62:10801

Gideon RK, Zhang F, Wu L, Sun B, Gu B (2015) Damage behaviors of woven basalt-unsaturated polyester laminates under low-velocity impact. J Compos Mater 49:2103-2118

Goldberg RK, Blinzler BJ, Binienda WK (2012) Modification of a macromechanical finite element-based model for impact analysis of triaxially braided composites. J Aero Eng 25:383-394

Gower HL, Cronin DS, Plumtree A (2008) Ballistic impact response of laminated composite panels. Int J Impact Eng 35:10008

Gu BH, Ding X (2005) A refined quasi-microstructure model for finite element analysis of three-dimensional braided composites under ballistic penetration. J Compos Mater 39:685-710

Ha SK, Jin KK, Huang Y (2008) Micro-mechanics of failure (MMF) for continuous fiber reinforced composites. J Compos Mater 42:1873-1895

Ha SK, Huang Y, Han HH, Jin KK (2010) Micromechanics of failure for ultimate strength predictions of composite laminates. J Compos Mater 44:2347-2361

Hahn HT (1973) Nonlinear behavior of laminated composites. J Compos Mater 7: 257-271

Hao W, Yuan Y, Yao X, Ma Y (2015) Computational analysis of fatigue behavior of 3D 4-directional braided composites based on unit cell approach. Adv Eng Softw 82:38-52 
Hart-Smith LJ (1998) Predictions of the original and truncated maximum-strain failure models for certain fibrous composite laminates. Compos Sci Technol 58:1151-1178

Hashin Z (1980) Failure criteria for unidirectional fiber composites. J Appl Mech 47:329-334

Heinrich C, Aldridge M, Wineman AS, Kieffer J, Waas AM, Shahwan KW (2013) The role of curing stresses in subsequent response, damage and failure of textile polymer composites. J Mech Phys Solids 61:1241-1264

Hoffman O (1967) The brittle strength of orthotropic materials. J Compos Mater 1:200-206

Hou JP, Petrinic N, Ruiz C, Hallett SR (2000) Prediction of impact damage in composite plates. Compos Sci Technol 60:273-281

Ji X, Khatri AM, Chia ES, Cha RK, Yeo BT, Joshi SC, Chen Z (2014) Multi-scale simulation and finite-element-assisted computation of elastic properties of braided textile reinforced composites. J Compos Mater 48:931-949

Jiang L, Zeng T, Yan S, Fang D (2013) Theoretical prediction on the mechanical properties of 3D braided composites using a helix geometry model. Compos Struct 100:511-516

Kaddour AS, Hinton MJ (2012) Benchmarking of triaxial failure criteria for composite laminates: comparison between models of 'Part (A)'of 'WWFE-II'. J Compos Mater 46:2595-2634

Kang H, Shan Z, Zang Y, Liu F (2016) Progressive damage analysis and strength properties of fiber-bar composites reinforced by three-dimensional weaving under uniaxial tension. Compos Struct 141:264-281

Kavousi Sisi M, Shakeri M, Sadighi M (2015) Dynamic response of composite laminated beams under asynchronous/repeated low-velocity impacts of multiple masses. Compos Struct 132:960-973

Lapczyk I, Hurtado JA (2007) Progressive damage modeling in fiber-reinforced materials. Compos Part A: Appl Sci Manuf 38:2333-2341

Li X (2010) Mesomechanical model for failure study of two dimensional triaxial braided composite materials. PhD Thesis, University of Akron. $\mathrm{OH}$.

Li X, Binienda WK, Littell JD (2009) Methodology for impact modeling of triaxial braided composites using shell elements. J Aerosp Eng 22:310-317

Li X, Binienda WK, Goldberg RK (2011) Finite-element model for failure study of two-dimensional triaxially braided composite. J Aero Eng 24:170-180

Littell JD, Binienda WK, Roberts GD, Goldberg RK (2009a) Characterization of damage in triaxial braided composites under tensile loading. J Aero Eng 22:270-279

Littell JD, Binienda WK, Arnold WA, Roberts GD, Goldberg RK (2009b) Effect of microscopic damage events on static and ballistic impact strength of triaxial braid composites. Compos Part A: Appl Sci Manuf 40:1846-1862

Liu KC, Chattopadhyay A, Bednarcyk B, Arnold SM (2011) Efficient multiscale modeling framework for triaxially braided composites using generalized method of cells. J Aero Eng 24:162-169

Lulu L, Haijun X, Na Z, Guangtao C, Yiming F, Weirong H (2013) Impact response and damage evolution of triaxial braided carbon/epoxy composites Part II: finite element analysis. Text Res J 83:1821-1835

Liu Y, Mahadevan S (2007) A unified multiaxial fatigue damage model for isotropic and anisotropic materials. Int J Fatigue 29:347-359

Lomov SV, Huysmans G, Luo Y, Parnas RS, Prodromou A, Verpoest I, Phelan FR (2001) Textile composites: modelling strategies. Compos Part A: Appl Sci Manuf 32:1379-1394

Lu Z, Wang C, Xia B, Yang Z (2013) Effect of interfacial properties on the uniaxial tensile behavior of three-dimensional braided composites. Comput Mater Sci 79:547-557

Ma P, Gao Z (2013) A review on the impact tension behaviors of textile structural composites. J Ind Text 44:572-604

Maimí P, Camanho PP, Mayugo JA, Dávila CG (2007) A continuum damage model for composite laminates: Part II-Computational implementation and validation. Mech Mater 39:909-919

Mao H, Mahadevan S (2002) Fatigue damage modelling of composite materials. Compos Struct 58:405-410

Mao JZ, Sun XS, Ridha M, Tan VBC, Tay TE (2013) A modeling approach across length scales for progressive failure analysis of woven composites. Appl Compos Mater 20:213-231

Matveev MY, Long AC, Jones IA (2014) Modelling of textile composites with fibre strength variability. Compos Sci Technol 105:44-50

Matzenmiller A, Lubliner J, Taylor RL (1995) A constitutive model for anisotropic damage in fiber-composites. Mech Mater 20:125-152

McGregor CJ, Vaziri R, Poursartip A, Xiao X (2007) Simulation of progressive damage development in braided composite tubes under axial compression. Compos Part A: Appl Sci Manuf 38:2247-2259
McLendon WR, Whitcomb JD (2012) Characteristic failure initiation sites in plain weave textile composites. J Compos Mater 47:3143-3161

Miravete A, Bielsa JM, Chiminelli A, Cuartero J, Serrano S, Tolosana N, De Villoria RG (2006) 3D mesomechanical analysis of three-axial braided composite materials. Compos Sci Technol 66:2954-2964

Montesano J, Fawaz Z, Behdinan K, Poon C (2013) Fatigue damage characterization and modeling of a triaxially braided polymer matrix composite at elevated temperatures. Compos Struct 101:129-137

Montesano J, Selezneva M, Levesque M, Fawaz Z (2015) Modeling fatigue damage evolution in polymer matrix Compos Struct and validation using in-situ digital image correlation. Compos Struct 125:354-361

Mouritz P, Bannister MK, Falzon PJ, Leong KH (1999) Review of applications for advanced three-dimensional fibre textile composites. Compos Part A: Appl Sci Manuf 30:1445-1461

Murakami S (1988) Mechanical modeling of material damage. J Appl Mech 55: 280-286

Murakami S (2012) Continuum damage mechanics: a continuum mechanics approach to the analysis of damage and fracture. Springer Science Business Media. Springer Ebooks 41(4):4731-4755.

Naik NK, Shembekar PS (1992) Elastic behavior of woven fabric composites: I_Lamina analysis. J Compos Mater 26:2196-2225

Nobeen NS, Zhong YC, Francis BAP, Ji XB, Chia ESM, Joshi SC, Chen Z (2016) Constituent materials micro-damage modeling in predicting progressive failure of braided fibre composites. Compos Struct 145:194-202

Paley M, Aboudi J (1992) Micromechanical analysis of composites by the generalized cells model. Mech Materials 14:127-139

Pan Z, Gu B, Sun B (2014) Longitudinal compressive behaviour of 3D braided composite under various temperatures and strain rates. Applied Physics A 118:1315-1337

Pankow M, Waas AM, Yen CF, Ghiorse S (2012) Modeling the response, strength and degradation of $3 \mathrm{D}$ woven composites subjected to high rate loading. Compos Struct 94:1590-1604

Paris PC, Gomez MP, Anderson WE (1961) A rational analytic theory of fatigue. Trend Eng 13:9-14

Paris F, Jackson KE (2001) A study of failure criteria of fibrous composite materials. NASA Center for AeroSpace Information (CASI). Hanover.

Pascal F, Navarro P, Marguet S, Ferrero JF (2015) On the modelling of low to medium velocity impact onto woven composite materials with a $2 \mathrm{D}$ semicontinuous approach. Compos Struct 134:302-310

Pinho S, lannucci L, Robinson P (2006) Physically based failure models and criteria for laminated fibre-reinforced composites with emphasis on fibre kinking Part II: FE implementation. Compos Part A: Appl Sci Manuf 37:766-777

Post NL, Case SW, Lesko JJ (2008) Modeling the variable amplitude fatigue of composite materials: A review and evaluation of the state of the art for spectrum loading. Int J Fatigue 30:2064-2086

Puck A, Schürmann H (1998) Failure analysis of FRP laminates by means of physically based phenomenological models. Compos Sci Technol 58:1045-1067

Puck A, Kopp J, Knops M (2002) Guidelines for the determination of the parameters in Puck's action plane strength criterion. Compos Sci Technol 62:371-378

Qi G, Du S, Zhang B, Tang Z, Yu Y (2014) Evaluation of carbon fiber/epoxy interfacial strength in transverse fiber bundle composite: Experiment and multiscale failure modeling. Compos Sci Technol 105:1-8

Qiao P, Yang M, Bobaru F (2008) Impact mechanics and high-energy absorbing materials: review. J Aero Eng 21:235-248

Quek SC, Waas AM, Shahwan KW, Agaram V (2003) Analysis of 2D triaxial flat braided textile composites. Int J Mech Sci 45:1077-1096

Rao MP, Duan Y, Keefe M, Powers BM, Bogetti TA (2009a) Modeling the effects of yarn material properties and friction on the ballistic impact of a plain-weave fabric. Compos Struct 89:556-566

Rao MP, Nilakantan G, Keefe M, Powers BM, Bogetti TA (2009b) Global/local modeling of ballistic impact onto woven fabrics. J Compos Mater 43:445-467

Rawal A, Saraswat H, Sibal A (2015) Tensile response of braided structures: a review. Text Res J 85:2083-2096

Rolfes R, Vogler M, Czichon S, Ernst G (2011) Exploiting the structural reserve of textile Compos Struct by progressive failure analysis using a new orthotropic failure criterion. Comput Struct 89:1214-1223

Rosen BW (1964) Tension failure of fibrous composites. AIAA J 2:1985-1991

Schultz JA, Garnich MR (2013) Meso-scale and multicontinuum modeling of a triaxial braided textile composite. J Compos Mater 47:303-314

Schwab M, Todt M, Wolfahrt M, Pettermann HE (2016) Failure mechanism based modelling of impact on fabric reinforced composite laminates based on shell elements. Compos Sci Technol 128:131-137 
Sevenois RDB, Van Paepegem W (2015) Fatigue damage modeling techniques for textile composites: review and comparison with unidirectional composite modeling techniques. Appl Mech Rev 67:21401

Sevkat E, Liaw B, Delale F, Raju BB (2009a) A combined experimental and numerical approach to study ballistic impact response of S2-glass fiber/ toughened epoxy composite beams. Compos Sci Technol 69:965-982

Sevkat E, Liaw B, Delale F, Raju BB (2009b) Drop-weight impact of plain-woven hybrid glass-graphite/toughened epoxy composites. Compos Part A: Appl Sci Manuf 40:1090-1110

Shokrieh MM, Lessard LB (2000) Progressive fatigue damage modeling of composite materials Part I: modelling. J Compos Mater 34:1056-1080

Silberschmidt W (2016) Dynamic deformation, damage and fracture in composite materials and structures. Woodhead Publishing. Cambridge.

Šmilauer V, Hoover CG, Bažant ZP, Caner FC, Waas AM, Shahwan KW (2011) Multiscale simulation of fracture of braided composites via repetitive unit cells. Eng Fract Mech 78:901-918

Sun B, Liu R, Gu B (2012a) Numerical simulation of three-point bending fatigue of four-step 3-D braided rectangular composite under different stress levels from unit-cell approach. Comput Mater Sci 65:239-246

Sun B, Zhang Y, Gu B (2013) Low-velocity impact response and finite element analysis of four-step 3-D braided composites. Appl Compos Mater 20:397-413

Sun B, Zhang R, Zhang Q, Gideon R, Gu B (2012b) Drop-weight impact damage of threedimensional angle-interlock woven composites. J Compos Mater 47:2193-2209

Tian Z, Yan Y, Luo H, Hong Y (2016) Parameterized unit-cell models for stiffness performance analyses of three-dimensional n-directional braided composites. J Reinf Plast Compos 35:1371-1386

Tolosana N, Carrera M, de Villoria RG, Castejon L, Miravete A (2012) Numerical analysis of three-dimensional braided composite by means of geometrical modeling based on machine emulation. Mech Adv Mater Struct 19:207-215

Tsai SW (1968) Strength theories of filamentary structures. Fundamental aspects of fiber reinforced plastic composites 3-11

Tsai SW, Wu EM (1971) A general theory of strength for anisotropic materials. J Compos Mater 5:58-80

Tserpes Kl, Labeas GN (2009) Mesomechanical analysis of non-crimp fabric composite structural parts. Compos Struct 87:358-369

Ullah H, Silberschmidt W (2015) Numerical analysis of the interactive damage mechanisms in two-dimensional carbon fabric-reinforced thermoplastic composites under low velocity impacts. J Compos Mater 49(25):3127-3143

Van Paepegem W, Degrieck J (2001) Fatigue degradation modelling of plain woven glass/epoxy composites. Compos Part A: Appl Sci Manuf 32:1433-1441

Wan Y, Wang Y, Gu B (2015) Finite element prediction of the impact compressive properties of three-dimensional braided composites using multi-scale model. Compos Struct 128:381-394

Wan Y, Sun B, Gu B (2016) Multi-scale structure modeling of damage behaviors of $3 \mathrm{D}$ orthogonal woven composite materials subject to quasi-static and high strain rate compressions. Mechan Mater 94:1-25

Wang C, Lu Z, Jin L (2015) A review on the mechanical performance and fatigue behavior of 3-D angle-interlock woven composites. J Text Ins 106:1306-1314

Wang C, Roy A, Chen Z, Silberschmidt W (2017a) Braided textile composites for sports protection: energy absorption and delamination in impact modelling. Mater Des. (under review)

Wang C, Zhong YC, Francis BAP, Ji X, Roy A, Silberschmidt W, Chen Z (2016a) Strength prediction for bi-axial braided composites by a multi-scale modelling approach. J Mater Sci 51:6002-6018

Wang H, Sun B, Gu B (2017b) Numerical modeling on compressive behaviors of 3-D braided composites under high temperatures at microstructure level. Compos Struct 160:925-938

Wang Y, Sun J, Cai D, Zhou G (2016b) Tensile properties and failure mechanism of a new 3D nonorthogonal woven composite material. Appl Compos Mater 23:1117-1135

Warren KC, Lopez-Anido RA, Vel SS, Bayraktar HH (2016) Progressive failure analysis of three-dimensional woven carbon composites in single-bolt, double-shear bearing. Compos Part B: Eng 84:266-276

Wong CC, Long AC, Sherburn M, Robitaille F, Harrison P, Rudd CD (2006) Comparisons of novel and efficient approaches for permeability prediction based on the fabric architecture. Compos Part A: Appl Sci Manuf 37:847-857

Wu L, Gu B (2014) Fatigue behaviors of four-step three-dimensional braided composite material: a meso-scale approach computation. Text Res J 84:1915-1930

Wu L, Sun B, Gu B (2014a) Numerical analyses of bending fatigue of four-step three-dimensional rectangular-braided composite materials from unit cell approach. J Text Ins 106:67-79
Wu L, Zhang F, Sun B, Gu B (2014b) Finite element analyses on three-point lowcyclic bending fatigue of 3-D braided composite materials at microstructure level. Int J Mech Sci 84:41-53

Xiao JR, Gama BA, Gillespie JW Jr (2007) Progressive damage and delamination in plain weave S-2 glass/SC-15 composites under quasi-static punch shear loading. Compos Struct 78:182-196

Xiao X, Kia HG, Gong XJ (2011) Strength prediction of a triaxially braided composite. Compos Part A: Appl Sci Manuf 42:1000-1006

Xie D, Salvi AG, Sun CE, Waas AM, Caliskan A (2006) Discrete cohesive zone model to simulate static fracture in $2 \mathrm{D}$ triaxially braided carbon fiber composites. J Compos Mater 40:2025-2046

Xu J (2011) Meso-scale finite element fatigue modelling of textile composite materials. University of Leuven

Xu L, Jin CZ, Ha SK (2015a) Ultimate strength prediction of braided textile composites using a multi-scale approach. J Compos Mater 49:477-494

Xu J, Lomov SV, Verpoest I, Daggumati S, Van Paepegem W, Degrieck J (2015b) A progressive damage model of textile composites on meso-scale using finite element method: Fatigue damage analysis. Comput Struct 152:96-112

Xu J, Lomov SV, Verpoest I, Daggumati S, Van Paepegem W, Degrieck J (2016) A comparative study of twill weave reinforced composites under tensiontension fatigue loading: Experiments and meso-modelling. Compos Struct 135:306-315

Ye L (1989) On fatigue damage accumulation and material degradation in composite materials. Compos Sci Technol 36:339-350

Yen CF (2002) Ballistic impact modeling of composite materials. In Proceedings of 7th Int LS-DYNA Conference Southfield, Michigan. 6;5-23

Zako M, Uetsuji Y, Kurashiki T (2003) Finite element analysis of damaged woven fabric composite materials. Compos Sci Technol 63:507-516

Zhang C, Binienda WK (2014) A meso-scale finite element model for simulating free-edge effect in carbon/epoxy textile composite. Mech Mater 76:1-19

Zhang C, Binienda WK, Goldberg RK, Kohlman LW (2014) Meso-scale failure modeling of single layer triaxial braided composite using finite element method. Compos Part A: Appl Sci Manuf 58:36-46

Zhang D, Chen L, Sun Y, Wang X, Zhang Y, Fu C (2015a) Meso-scale progressive damage of 3D five-directional braided composites under transverse compression. J Compos Mater 50:3345-3361

Zhang C, Curiel-Sosa JL, Bui TQ (2017a) Comparison of periodic mesh and free mesh on the mechanical properties prediction of 3D braided composites. Compos Struct 159:667-676

Zhang C, Li N, Wang W, Binienda WK, Fang H (2015b) Progressive damage simulation of triaxially braided composite using a 3D meso-scale finite element model. Compos Struct 125:104-116

Zhang ZF, Wang LK, Silberschmidt W (2017b) Damage response of steel plate to underwater explosion: Effect of shaped charge liner. Int J Impact Eng 103:38-49

Zhang ZF, Wang LK, Silberschmidt W, Wang SP (2016a) SPH-FEM simulation of shaped-charge jet penetration into double hull: A comparison study for steel and SPS. Compos Struct 155:135-144

Zhang T, Yan Y, Li J, Luo H (2016b) Low-velocity impact of honeycomb sandwich composite plates. J Reinf Plast Compos 35:8-32

Zhao C, Huang Y, Chen Z, Ha SK (2016) Progressive failure prediction of a landing gear structure of braided composites. Compos Struct 161:407-418

Zeng XS, Tan VBC, Shim VP (2006) Modelling inter-yarn friction in woven fabric armour. Int J Numer Meth Eng 66:1309-1330

Zhong S, Guo L, Liu G, Lu H, Zeng T (2015) A continuum damage model for three-dimensional woven composites and finite element implementation. Compos Struct 128:1-9

Zhong YC, Suraj R, Wang C, Chia ESM, Joshi SC, Chen Z (2017) Damage advancement behavior in braided composite structure for mini aerial vehicle. Mechan Adv Mater Struct. doi:10.1080/15376494.2017.1310335

Zhou Y, Lu Z, Yang Z (2013) Progressive damage analysis and strength prediction of 2D plain weave composites. Compos Part B: Eng 47:220-229

Zhou H, Zhang W, Liu T, Gu B, Sun B (2015) Finite element analyses on transverse impact behaviors of 3-D circular braided composite tubes with different braiding angles. Compos Part A: Appl Sci Manuf 79:52-62 